\title{
Nuevas formas de contaminación y tributación. Contaminación acústica y paisajística en la fiscalidad española
}

\author{
Francisco Javier Alonso Madrigal \\ Profesor doctor de Derecho Financiero y Tributario \\ Universidad Pontificia Comillas de Madrid
}

Recibido: 30.10 .09

Aceptado: 15.12.09

\begin{abstract}
Resumen: El ruido y la incidencia en el paisaje son dos formas de daño medioambiental que comienzan a ser tomadas en cuenta por el legislador como justificación para la creación de alguna figura tributaria, y son también propuestas por la doctrina e instancias europeas como criterio orientador para la modificación de otras. Tanto el recargo sobre la cuantía de la tasa de aterrizaje creado por la Ley de Calidad del Aire y Protección de la Atmósfera, y las tasas por servicios de inspección previstas en la Ley del Ruido han sido creados en respuesta a la contaminación acústica; además de estos, otros tributos podrían desempeñar un papel en el desincentivo de las actividades que producen dicha contaminación. Por lo que se refiere a la contaminación paisajística, el impuesto medioambiental aragonés sobre el daño causado por la instalación de transportes por cable es el que de forma más explícita proclama como su objeto la protección del paisaje. Otros tributos autonómicos, por la similitud que guardan con el impuesto aragonés en su cuantificación, podrían fundamentarse en la misma finalidad.
\end{abstract}

Palabras clave: Tributos ecológicos. Contaminación acústica y paisajística.

Abstract: Noise and landscape pollution are two kinds of environmental damage that are beginning to be considered by lawmakers as a reason for establishing new taxes and are also suggested by scholars and European agencies as a course for changing some of the actual ones. The surcharge on the Landing Charge established by the Air Quality and Atmosphere Protection Law and the inspection charges included in the Noise Law have been created as an answer to noise pollution. Moreover, there are some other taxes that could play a role in the fight against noise pollution activities. With regarding to landscape pollution, the Aragon' environmental tax on the damage caused by the wire transport facilities is the one that states more plainly his landscape protection objet. Other regional taxes, that are similar to the Aragon one in the way they calculate their tax, could be considered as justified by the same goal.

Key words: Enviromental taxation. Noise and landscape pollution.

Sumario: I. Introducción.--II. Tasa de aterrizaje y ruido.--III. Tasas municipales por licencia de apertura y control de ruidos.--IV. El ruido y el impuesto municipal sobre vehículos de tracción mecánica.-V. Un eventual recargo autonómico sobre el impuesto estatal especial sobre determinados medios de transporte y el ruido.-VI. La imposición sobre 
los hidrocarburos y el ruido.-VII. El impuesto sobre el daño medioambiental causado por la instalación de transportes por cable de la Comunidad Autónoma de Aragón y el paisaje.--VIII. El impuesto sobre el daño medioambiental causado por las grandes áreas de venta de la Comunidad Autónoma de Aragón y el paisaje.

\section{Introducción}

El concepto de medio ambiente se muestra en permanente expansión conforme los niveles crecientes de calidad de vida en las sociedades avanzadas van demandando de los poderes públicos una esfera más amplia y más estricta de protección de aquella. Formas de incidencia en el medio ambiente que en el pasado se consideraban tolerables o simplemente inevitables pasan a ser consideradas como inmisiones ilegítimas, ataques que han de ser tratados como tales y corregidos. Así ha sucedido con las formas de contaminación que son objeto del presente trabajo, la acústica y la paisajística, que aunque desde siempre se han contemplado como indeseables, han sido objeto de una creciente atención por parte de los distintos medios con los que cuenta el ordenamiento para encauzar o prohibir las actividades socialmente indeseables. Entre estos medios ocupan una posición destacada los tributos medioambientales que, cada vez en mayor número, son introducidos en un sistema fiscal en el que los tributos parecen requerir una justificación adicional al gravamen de la capacidad económica manifestada por el sujeto para ser aceptados política y socialmente. Así comienza a suceder en nuestro ordenamiento tributario en relación con el ruido y la incidencia en el paisaje, donde ya ha comenzado a hacerse referencia a ellos como justificación de alguna figura tributaria vigente y se proponen, desde la doctrina y desde instancias europeas, adaptaciones de otras existentes a dicha finalidad.

Desde el punto de vista de la justificación del tributo ambiental en la capacidad económica, resulta difícil, a mi juicio, basarla en la pretendidamente demostrada por quienes no asumen las externalidades provocadas por dicha contaminación, lo que equivaldría a la utilización gratuita de unos factores productivos; capacidad económica esta que sería entendida, no como capacidad de pago, sino como capacidad de disponer de riqueza ${ }^{1}$. No obstan-

\footnotetext{
${ }^{1}$ Al respecto Herrera Molina, P. M.: «Derecho Tributario ambiental: la introducción del interés ambiental en el ordenamiento tributario», Marcial Pons, 2000, p. 159. Defiende esta tesis Cors Meya X.: «Impuesto sobre grandes establecimientos comerciales (I.G.E.C.)» en Revista de Derecho Financiero y Hacienda Pública, núm. 263, 2002, pp. 17-18. Una acertada crítica a esta postura en Ortiz Calle E.: «Fiscalidad ambiental y límites al poder tributario autonómico (Comentario a la sentencia 289/2000, de 30 de noviembre, del Tribunal Constitucional, del Impuesto balear sobre instalaciones que inciden en el Medio Ambiente», en Revista interdisciplinar de gestión ambiental, núm. 27/2001.
} 
te, el art. 45.2 de la Constitución española establece lo siguiente: «Los poderes públicos velarán por la utilización racional de todos los recursos naturales, con el fin de proteger y mejorar la calidad de vida y defender y restaurar el medio ambiente, apoyándose en la indispensable solidaridad colecti$v a »$, referencia esta última a la «indispensable solidaridad colectiva» que se ha entendido por parte de la doctrina como una referencia directa a la intervención del legislador tributario con dicha finalidad ${ }^{2}$.

En el Libro Verde sobre la utilización de instrumentos de mercado en la política de medio ambiente y otras políticas relacionadas ${ }^{3}$ se justifica, desde una perspectiva económica, el recurso a instrumentos basados en el mercado, como los tributos, para corregir sus deficiencias de una forma rentable, utilizando las señales del propio mercado para hacerlo, lo que les proporciona una flexibilidad que puede reducir sustancialmente los costes de las mejoras del medio ambiente. Los instrumentos de mercado ofrecerían ciertas ventajas respecto a los instrumentos normativos, como limitaciones, prohibiciones o sanciones:

«Mejoran las señales de los precios, al otorgar un valor a los beneficios y costes externos de las actividades económicas, de modo que los actores económicos los tienen en cuenta y modifican su comportamiento para paliar las repercusiones negativas, medioambientales y de otro tipo, y aumentar las positivas.

- Permiten a la industria un mayor grado de flexibilidad para alcanzar los objetivos y rebajan de esta forma los costes globales de cumplimiento.

- Incitan a las empresas a introducir, a más largo plazo, innovaciones tecnológicas, con el fin de seguir reduciendo el impacto negativo en el medio ambiente ("eficiencia dinámica").

- Favorecen el empleo cuando se utilizan en el contexto de la reforma de los impuestos ambientales o de la reforma fiscal» ${ }^{4}$.

Una correcta utilización de los tributos ambientales para corregir los fallos de mercado, que sea coherente con sus fundamentos teóricos, exigiría un cálculo previo de las externalidades negativas provocadas por la contaminación (así como de las eventuales externalidades positivas provocadas también por la actividad económica contaminante) que se reflejaría en la cuan-

${ }^{2}$ Chico de la Cámara P.: «La regla de la no confiscatoriedad como límite a la tributación medioambiental» en Becker, F., Cazorla L. M. y Martínez-Simancas J., Tratado de Tributación Medioambiental. Vol. I. Aranzadi, 2008, p. 162. En contra, Herrera Molina P.: «El principio 'quien contamina paga'» en Becker, F., et al. cit. Tratado... p. 192.

${ }^{3}$ Bruselas, 28.3.2007 COM(2007) 140 final.

${ }^{4}$ Libro Verde sobre la utilización de instrumentos de mercado en la política de medio ambiente y otras políticas relacionadas, Bruselas, 28.3.2007 COM(2007) 140 final. pp. 3 y 4 . 
tía del tributo. Si el problema práctico de determinar los costes externos que deben ser internalizados mediante el empleo de instrumentos económicos como los tributos es común a toda la tributación medioambiental, se hace especialmente acusado en lo que se refiere a formas de contaminación como la acústica y la paisajística, de contornos aún imprecisos y con indudables dificultades técnicas, no ya en la valoración del daño, sino en la medición misma de la incidencia en el medio ambiente; ello hace inevitable la determinación política, y no técnica, del importe del coste ocasionado por dichas inmisiones cuya internalización se considera adecuado o soportable ${ }^{5}$ y la consiguiente proyección sobre los tributos medioambientales que pretenden corregir estas formas de contaminación de una justificada duda sobre si su verdadera finalidad va más allá de la meramente recaudatoria.

Tal y como señala la Ley del Ruido ${ }^{6}$ en su exposición de motivos «el mandato constitucional de proteger la salud (artículo 43 de la Constitución) y el medio ambiente (artículo 45 de la Constitución) engloban en su alcance la protección contra la contaminación acústica. Además, la protección constitucional frente a esta forma de contaminación también encuentra apoyo en algunos derechos fundamentales reconocidos por la Constitución, entre otros, el derecho a la intimidad personal y familiar, consagrado en el artículo 18.1». Así lo ha venido reconocido también el TC en pronunciamientos como la STC 16/2004, de 23 febrero ${ }^{7}$.

${ }^{5}$ Herrera Molina, op. últ. cit. pp. 189 y 196.

${ }^{6}$ Ley 37/2003, de 17 noviembre, BOE 18 noviembre 2003, núm. 276.

${ }^{7}$ RTC 2004\16. «Desde la perspectiva de los derechos fundamentales implicados, debemos comenzar nuestro análisis recordando la posible afección al derecho a la integridad física y moral. A este respecto, habremos de convenir en que, cuando la exposición continuada a unos niveles intensos de ruido ponga en grave peligro la salud de las personas, esta situación podrá implicar una vulneración del derecho a la integridad física y moral (art. 15 $C E$ ). En efecto, si bien es cierto que no todo supuesto de riesgo o daño para la salud implica una vulneración del art. 15 CE, sin embargo cuando los niveles de saturación acústica que deba soportar una persona, a consecuencia de una acción u omisión de los poderes públicos, rebasen el umbral a partir del cual se ponga en peligro grave e inmediato la salud, podrá quedar afectado el derecho garantizado en el art. 15 CE.

Respecto a los derechos del art. $18 \mathrm{CE}$, debemos poner de manifiesto que en tanto el art. $8.1 \mathrm{CEDH}$ reconoce el derecho de toda persona "al respeto de su vida privada y familiar, de su domicilio y de su correspondencia”, el art. 18 CE dota de entidad propia y diferenciada a los derechos fundamentales a la intimidad personal y familiar (art. 18.1) y a la inviolabilidad del domicilio (art. 18.2). Respecto del primero de estos derechos fundamentales insistimos en que este Tribunal ha precisado que su objeto hace referencia a un ámbito de la vida de las personas excluido tanto del conocimiento ajeno como de las intromisiones de terceros, y que la delimitación de este ámbito ha de hacerse en función del libre desarrollo de la personalidad. De acuerdo con este criterio, hemos de convenir en que uno de dichos ámbitos es el domiciliario por ser aquel en el que los individuos, libres de toda sujeción a los usos y convenciones sociales, ejercen su libertad más íntima (SSTC 22/1984, de 17 de febrero, F. 5; 137/1985, de 17 de octubre, F. 2, y 94/1999, de 31 de mayo, F. 5). 
Entre los objetivos y ámbitos prioritarios de actuación sobre el medio ambiente y la salud y la calidad de vida que enumera el art. 7 de la Decisión 1600/2002/CE del Parlamento Europeo y del Consejo, de 22 de julio de 2002, por la que se establece el Sexto Programa de Acción Comunitario en Materia de Medio Ambiente, está el de «reducir sustancialmente el número de personas afectadas periódicamente por niveles medios de ruido prolongado, en particular los derivados del tráfico que, según los estudios científicos, tienen efectos perjudiciales para la salud humana, y preparar la fase siguiente de los trabajos sobre la Directiva sobre el ruido», para cuyo logro se prevén como actuaciones prioritarias (letra g): «completar y seguir mejorando las medidas, incluidos los procedimientos adecuados de homologación, sobre emisiones acústicas de servicios y productos, en especial los vehículos de motor, incluidas medidas para reducir el ruido causado por la interacción entre los neumáticos y el pavimento vial que no comprometan la seguridad vial, del material rodado ferroviario, las aeronaves y la maquinaria estática» $\mathrm{y}$ «crear y aplicar instrumentos para mitigar el ruido del tráfico cuando proceda, por ejemplo mediante la reducción de la demanda de transporte, la opción en favor de medios de transporte menos ruidosos, y el fomento de medidas técnicas y de una planificación sostenible del transporte».

En nuestra doctrina, el profesor Zornoza se muestra partidario de la recuperación de los arbitrios o impuestos con fines no fiscales, en el ámbito local, con la finalidad de hacer posible el empleo de los instrumentos tributarios al servicio de políticas públicas en materia de ruido o contaminación acústica; dado que se trata de una materia en la que las regulaciones mantienen niveles de tolerancia muy amplios, lo que hace posible una contaminación residual que puede contribuir a reducir los impuestos sobre el ruido, existentes en el panorama comparado y de los que existen antecedentes en nuestro sistema que sería conveniente recuperar ${ }^{8}$.

Teniendo esto presente, debemos advertir que, como ya se dijo en la STC 119/2001, de 24 de mayo, F. 6, una exposición prolongada a unos determinados niveles de ruido, que puedan objetivamente calificarse como evitables e insoportables, ha de merecer la protección dispensada al derecho fundamental a la intimidad personal y familiar, en el ámbito domiciliario, en la medida en que impidan o dificulten gravemente el libre desarrollo de la personalidad, siempre y cuando la lesión o menoscabo provenga de actos u omisiones de entes públicos a los que sea imputable la lesión producida». F. J. 4.

${ }^{8}$ Zornoza J.: «Tributación ambiental y turismo: otras experiencias» en Cuadernos de sostenibilidad y patrimonio natural. 12/2007 Tributación ambiental en España, p. 29. Puede citarse a este respecto el conocido precio público regulado en la «Ordenanza reguladora por emitir ruidos y malos olores» del ayuntamiento coruñés de Cerceda, que grava la emisión de ruidos por encima de 30 decibelios emitidos desde los centros de trabajo, en el que la cuota se determina en función del volumen y la duración de la emisión de los ruidos, así como de su reiteración a lo largo del día o la semana. Precio público que no es sino un auténtico impuesto municipal sobre el ruido como los propugnados por el citado profesor, aunque ciertamente no está previsto en la Ley Reguladora de Haciendas locales ni grava la contaminación acústica residual, sino los niveles de ruido por encima de los lícitos. 
La utilización de los tributos para la protección del medio ambiente de la contaminación acústica podría plantear un problema de redundancia o exceso de protección cuando el daño ocasionado por ella es objeto de resarcimiento en vía civil; en supuestos en los que, al ser posible individualizar y medir el daño causado a sujetos determinados y determinar su responsable, esté reparado a través de una indemnización. Sería el caso, por ejemplo, de la eventual concurrencia entre las indemnizaciones a los perjudicados por la contaminación acústica causada por la huella sonora de un aeropuerto, exigidas a una compañía aérea, y la tasa de aterrizaje satisfecha por esta en función del nivel de ruido emitido por sus aeronaves. Si el fundamento del tributo ambiental está en la internalización del coste que supone el daño al medio ambiente, dicha justificación desaparecería cuando el coste por dicho daño es satisfecho por el causante en forma de indemnización.

En supuestos en los que puede producirse dicho solapamiento, parece más adecuado, en vía de principio, limitar la utilización del instrumento tributario para desincentivar la contaminación acústica que tiene un origen o unos afectados que no sea posible identificar de forma cierta a efectos de la eventual reparación del daño. Estos serían los causados por fuentes difusas de ruido, aunque su acumulación pueda producir un daño a sujetos concretos, y los causados a un conjunto no determinado de sujetos, aunque el causante de la contaminación acústica sea identificable. O bien los que causan un daño que se encuentra por debajo del umbral que hace económicamente viable el ejercicio de una acción civil de resarcimiento pero, no obstante, se entiende necesario desincentivar su emisión. No obstante, una vez limitado el tributo a los supuestos y a los importes que no pueden ser objeto de resarcimiento, nada impide exigirlo cuando se produce un daño fuera de dichos supuestos o mayor de tales importes: por ejemplo, puede exigirse una mayor tasa ${ }^{9}$ por licencia de apertura a quienes desarrollan su actividad originando una contaminación acústica mayor, pero que se encuentra dentro de los umbrales lícitos tanto desde el punto de vista civil como administrativo, y exigir la reparación civil cuando se exceden dichos umbrales y se causa un daño cuantificable a un sujeto también identificable.

Como se ha señalado, en la legislación tributaria española encontramos algunas figuras en las que, aún de forma incipiente, ya se tiene presente el ruido como elemento configurador del tributo; como en la tasa de aterrizaje y las tasas municipales por licencia de apertura y control de ruidos. Junto a

${ }^{9}$ Aunque en el caso de las tasas el fundamento del tributo descansaría en el principio del beneficio y, por lo tanto, el coste a internalizar a través de ellas es, al menos en primera instancia, el coste que tiene el servicio provocado por el obligado tributario a la Administración, más que el deterioro del medio ambiente, que solo sería utilizado como criterio de reparto de dicho coste administrativo entre los obligados. 
ellas, existen en la actualidad una serie de impuestos que, por su naturaleza y estructura, podrían ser utilizados de forma idónea como instrumentos de mercado para el desincentivo de la contaminación acústica y, de hecho, se propone desde diversas instancias su utilización con esta finalidad.

Por lo que se refiere al paisaje, para el TC -ya desde su fundamental sentencia $102 / 1995^{10}$ - este constituiría una «noción estética, cuyos ingredientes son naturales -la tierra, la campiña, el valle, la sierra el mar- y culturales, históricos, con una referencia visual, el panorama o la vista, que a finales del pasado siglo obtiene la consideración de recurso, apreciado antes como tal por las aristocracias, generalizado hoy como bien colectivo, democratizado en suma y que, por ello, ha de incorporarse al concepto constitucional del medio ambiente como reflejan muchos de los Estatutos de Autonomía»; en opinión del alto tribunal, el paisaje «no es solo una realidad objetiva sino un modo de mirar, distinto en cada época y cada cultura», que se ha incorporado a los elementos naturales físicamente constitutivos del concepto de medio ambiente.

$\mathrm{El}$ «conservar y restaurar adecuadamente las zonas de importante valor paisajístico, incluidas las zonas cultivadas y las sensibles» aparece recogido entre las actuaciones prioritarias para la consecución de los objetivos prioritarios de actuación en los ámbitos de la naturaleza y la biodiversidad del art. 6 de la Decisión 1600/2002/CE del Parlamento Europeo y del Consejo, de 22 de julio de 2002, por la que se establece el Sexto Programa de Acción Comunitario en Materia de Medio Ambiente.

En opinión del profesor Rosembuj: «El paisaje, como tal, puede ser objeto de impuesto ambiental, pero, sin adornos. La apreciación no es solo estética, es también, si se puede decir, memorial. Envoltura visual de los ecosistemas naturales o fabricados, favorece la percepción visual del medio considerado y al mismo tiempo sintetiza la memoria (constituida por los modos de ocupación del medio). El paisaje en su contexto como integrador y revelador del bien ambiental, desprovisto de retórica elemental» ${ }^{11}$. En opinión de este autor: «Hay, bien es cierto, zonas fronterizas en las que el bien ambiental está territorializado o el territorio es, en sí mismo, bien ambiental. Es el caso (...) del paisaje entendido como forma del ambiente o, como dice Predieri, el paisaje es el ambiente visible: la forma del ambiente entendida como espacio visible» ${ }^{12}$. Para este autor: «La fiscalidad territorial no tiene, entonces, por qué coincidir con la ambiental y, a la inversa, la fiscalidad ambiental tampoco queda vinculada, automáticamente, al territorio.

${ }^{10}$ Sentencia núm. 102/1995 de 26 junio. RTC 1995\102. FJ 6..

${ }^{11}$ Rosembuj T.: «Los impuestos ambientales en las comunidades autónomas» en Quincena Fiscal, núm. 9, 2007, p. 13.

${ }^{12}$ Rosembuj T.: Op. ult. cit. p. 13. 
Solo cuando el territorio la cosa física proyecte valor intangible podría decirse que territorio y ambiente podrían compartir el tributo, positivo o negativo, ambiental y territorial como objeto único de ambos» ${ }^{13}$.

La íntima conexión entre protección del territorio y del paisaje, como proyección, en la terminología de Rosenbuj, del valor intangible o plus valor inmaterial de aquel, se pone de manifiesto en alguno de los impuestos autonómicos medioambientales, como el impuesto sobre el daño causado al medio ambiente por la instalación de transportes por cable o el impuesto sobre el daño medioambiental causado por las grandes áreas de venta de la Comunidad Autónoma de Aragón y otros tributos autonómicos similares.

Aunque los hechos que producen el deterioro paisajístico tengan un carácter material, tangible, que puede ser medido y valorado de forma objetiva, el propio daño ambiental en el paisaje no puede serlo realmente de la misma forma. Si la constatación misma de que un cambio en el paisaje causado por una actividad humana es constitutivo de un daño ambiental que debe ser reparado está inevitablemente teñida de un alto grado de subjetividad, cuánto más lo estará el medir si dicho daño es mayor o menor. Traducir ese daño a una valoración económica que pueda tomarse como referencia para la determinación de los elementos de cuantificación de un tributo ambiental resulta una tarea seguramente imposible. Quizá por ello, en los tributos medioambientales en los que se encuentra una referencia a la protección del paisaje o en los que, al menos, cabría entender de su regulación que aquella se encontraría entre sus objetivos, el daño en el paisaje únicamente es aludido tangencialmente y entre otras formas de contaminación frente a las que el tributo pretendería reaccionar. Por lo que se refiere a sus elementos de cuantificación, aun cuando pueda establecerse un vínculo racional entre ellos y la existencia de un daño en el paisaje, difícilmente puede admitirse una correlación real entre ellos y la intensidad de un daño tan difícilmente mensurable.

\section{Tasa de aterrizaje y ruido}

A favor del establecimiento de un sistema de tasas por la tolerancia de actividades económicas legítimas pero indeseables, como las que producen contaminación acústica, se pronuncia Puig ${ }^{14}$, aunque, en opinión de Herrera, para evitar la inseguridad jurídica que esto podría suponer, sería convenien-

${ }^{13}$ Rosembuj, T.: «Los impuestos ambientales de las comunidades autónomas» en Cuadernos de sostenibilidad y patrimonio natural. 12/2007 Tributación ambiental en España, p. 45 .

${ }^{14}$ Puig Ventosa, I.: «Fiscalidad ambiental local», Fundación Carles Pi i Sunyer, Barcelona, 2004, p. 177. 
te que la ley detallara los criterios de su establecimiento y cuantificación ${ }^{15}$. Así lo ha hecho la Ley 34/2007, de 15 de noviembre, de Calidad del Aire y Protección de la Atmósfera ${ }^{16}$, al modificar la tasa de aterrizaje regulada por la Ley 14/2000, de 29 de diciembre, de Medidas Fiscales, Administrativas y del Orden Social ${ }^{17}$, cuyo artículo 11 configuró la tasa de aterrizaje vigente desde el 1 de enero de 2001.

El hecho imponible de la tasa es «la utilización de las pistas de los aeropuertos civiles y de utilización conjunta, y de las bases aéreas abiertas al tráfico civil, por las aeronaves, y la prestación, por parte de la entidad pública empresarial Aeropuertos Españoles y Navegación Aérea de los servicios precisos para dicha utilización, distintos de la asistencia en tierra a las aeronaves, pasajeros y mercancías». Son sujetos pasivos de la tasa «las compañías aéreas y las restantes personas físicas, jurídicas o entidades que utilicen las pistas o perciban los servicios que constituyen el hecho imponible de la misma», estableciéndose una exención de carácter subjetivo a favor de «las aeronaves de Estado españolas, las aeronaves que presten servicio para las Comunidades Autónomas y otras Corporaciones locales, siempre y cuando realicen servicios públicos no comerciales, y las aeronaves de Estado extranjeras, en el caso de que los Estados a que pertenezcan concedan análoga exención a las aeronaves de Estado españolas».

La base imponible de la tasa de aterrizaje «la constituye el peso máximo de las aeronaves al despegue, expresado en toneladas métricas, tal como figura en el certificado de aeronavegabilidad, o en el manual de vuelo de la misma, o en cualquier otro documento oficial equivalente». Sobre dicha base imponible se aplica una tarifa de tipos específicos por cada tonelada métrica $(\mathrm{Tm})$, tarifa progresiva de tres tramos en función del peso del avión (porción de peso hasta $10 \mathrm{Tm}$, comprendida entre 10 y $100 \mathrm{Tm}$ y superior a $100 \mathrm{Tm}$ ); dicha tarifa varía en función del tipo de vuelo (vuelos del espacio económico europeo, vuelos internacionales o vuelos de entrenamiento) y de la categoría del aeropuerto (primera, segunda o tercera categoría). Una tarifa más elevada que no varía en función de estos dos últimos elementos se establece para las operaciones fuera del horario operativo del aeropuerto.

Sobre la tasa de aterrizaje, la Ley 34/2007, de 15 de noviembre, de Calidad del Aire y Protección de la Atmósfera ${ }^{18}$, en su Disposición Final Segunda, como se ha adelantado, viene a establecer una suerte de recargo sobre la cuantía de la tasa de aterrizaje tal y como estaba hasta entonces configurada. Según declara la ley en su exposición de motivos, su finalidad es la de «desincentivar el uso de aeronaves ruidosas mediante la aplicación de penalizaciones sobre

${ }^{15}$ Herrera Molina P. M.: «El principio...», cit. p. 206.

${ }^{16}$ BOE 16 noviembre 2007, núm. 275.

${ }^{17}$ BOE 30 diciembre 2000, núm. 313; rect. BOE 29 junio 2001, núm. 155.

${ }^{18}$ BOE 16 noviembre 2007, núm. 275. 
el importe a pagar por aterrizaje a aquellas aeronaves que superen los límites establecidos, sin pretender la recuperación de los costes asociados a los servicios de mitigación, control y vigilancia del ruido en los aeropuertos». Dicho recargo solamente aplicable inicialmente en los aeropuertos de Madrid Barajas y Barcelona, y posteriormente ampliado a los de Alicante, Málaga, Palma de Mallorca, Gran Canaria, Tenerife Sur y Valencia ${ }^{19}$, a los vuelos internacionales y del espacio económico europeo, no se aplica a los vuelos de entrenamiento ni a aquellos fuera del horario operativo del aeropuerto. El importe se establece en función de la franja horaria en que se produzca o el aterrizaje o el despegue y de la clasificación acústica de cada aeronave.

La categoría acústica de cada aeronave se determina en función del denominado «margen acumulado», definido como la cifra expresada en EPNdB (ruido efectivo percibido en decibelios) obtenida sumando las diferencias entre el nivel de ruido determinado y el nivel certificado de ruido en cada uno de los tres puntos de mediciones del ruido de referencia tal y como se definen en el volumen 1, segunda parte, capítulo 3, anexo 16 del Convenio sobre Aviación Civil Internacional. El ruido certificado es el que figure en el certificado de ruido de la aeronave, mientras que el ruido determinado es un estándar teórico que se establece como una suerte de límite máximo en función del peso de la aeronave y, en el caso del ruido de despegue, de su número de motores. Cuanto menor es el margen acumulado, más cerca está el ruido certificado de la aeronave del límite máximo constituido por el ruido determinado y, por tanto, más alto es su volumen de ruido. La categoría 1 está integrada por las aeronaves cuyo margen acumulado sea inferior a $5 \mathrm{EPNdB}$; la categoría 2, por las aeronaves cuyo margen acumulado esté comprendido entre $5 \mathrm{EPNdB}$ y $10 \mathrm{EPNdB}$; la categoría 3, por las aeronaves cuyo margen acumulado esté comprendido entre 10 EPNdB y 15 EPNdB; y la categoría 4, por aeronaves cuyo margen acumulado sea superior a 15 EPNdB.

El recargo solamente se establece para las categorías 1 y 2 , las más ruidosas, y se duplica para la franja horaria que va de las 23.00 a las 6.59.

\begin{tabular}{lcc}
\hline Clasificación acústica & $\begin{array}{c}\text { De } 7.00 \text { a 22.59 (hora local) } \\
\text { Porcentaje }\end{array}$ & $\begin{array}{c}\text { De 23.00 a 6.59 (hora local) } \\
\text { Porcentaje }\end{array}$ \\
\hline Categoría 1 & 70 & 140 \\
Categoría 2 & 20 & 40 \\
Categoría 3 & 0 & 0 \\
Categoría 4 & 0 & 0 \\
\hline
\end{tabular}

${ }^{19}$ Art. 81 de la Ley 2/2008, de 23 diciembre, de Presupuestos Generales del Estado para el año 2009. BOE 24 diciembre 2008, núm. 309. En él se establece una bonificación para dichos aeropuertos en el ejercicio 2009 en un 65\% de su importe y en 2010, en un 35\% de su importe. 
Desde el punto de vista de la naturaleza del tributo, habría que señalar que mientras la tasa de aterrizaje propiamente dicha se configura, como tasa que es, sobre la base del principio de equivalencia o reparto del coste del bien o servicio entre los usuarios de este y respondería al principio de justicia conmutativa, el porcentaje adicional que habría que exigir en función del ruido tiene la naturaleza de tributo ecológico, configurado sobre la base del principio «quien contamina paga», basado en criterios de justicia social y con una finalidad preventiva e incentivadora ${ }^{20}$. Como la propia exposición de motivos de la Ley de Calidad del Aire afirma expresamente, el recargo no pretende «la recuperación de los costes asociados a los servicios de mitigación, control y vigilancia del ruido en los aeropuertos», que es lo que correspondería a una tasa por servicios o actividades que se refieran, afecten o beneficien de modo particular a los sujetos pasivos.

Cabría preguntarse si estamos en este caso ante una tasa por aprovechamiento especial de bienes ambientales, aunque no tengan la consideración de demaniales, en la medida en que se tolere un cierto aprovechamiento especial de ellos que implique un concreto deterioro; en la línea propugnada por un importante sector doctrinal ${ }^{21}$ que establece una traslación del principio rector de la tributación ambiental -«quien contamina paga»- a la determinación de su importe, por el importe de los costes sociales que este produzca o por la utilidad que obtiene el sujeto que contamina.

En cualquier caso, el mezclar en una única figura tributaria una tasa y un recargo de naturaleza ecológica, sea tasa o impuesto, se revela disfuncional, puesto que los criterios de cuantificación a los que conducen uno y otro principio deberían ser diferentes. No parece, en definitiva, muy razonable que el desincentivo al uso de aeronaves ruidosas que pretende la aplicación del porcentaje del recargo esté determinada por el importe de la tasa de aterrizaje propiamente dicha, fijado en función de otros parámetros completamente distintos e incluso incongruentes con dicha finalidad.

Así, en primer lugar, dado que el peso de la aeronave es directamente determinante de la base sobre la que se aplica el porcentaje, dos aeronaves con el mismo margen acumulado, es decir, con la misma diferencia en cuanto a nivel de ruido con el nivel de ruido determinado, van a pagar un recargo diferente si su peso es diferente; cuando podría pensarse que, a igualdad de nivel de ruido, es más «eficiente» la aeronave de mayor peso. Cabe incluso que, aeronaves cuya clasificación acústica está en la categoría 2, cuyo nivel de ruido certificado es inferior al de las de categoría 1, paguen un recar-

${ }^{20}$ Herrera Molina: «El principio...», cit. p. 194.

${ }^{21}$ Calvo Verjez J.: «Las tasas medioambientales en el sistema tributario autonómico y local: algunas consideraciones», en Nueva Fiscalidad, núm.3/2004, pp. 78 y ss. y doctrina allí citada. 
go superior a ellas por el mero hecho de que su peso sea mayor, aunque la propia clasificación legal las califique como más «eficientes» en términos del ruido que generan. En segundo lugar, no parece que exista, en cuanto al nivel de ruido, diferencias entre los vuelos realizados en el espacio económico europeo y los vuelos internacionales, pero el porcentaje se aplicará sobre una base mayor, para la misma aeronave, si realiza un vuelo internacional. En tercer lugar, aunque actualmente el recargo se exija tan solo en algunos de los aeropuertos españoles de primera categoría ${ }^{22}$, tampoco parece adecuado que, si el recargo se exige en el futuro en aeropuertos de segunda o tercera categoría, el desincentivo que este supone sea inferior, puesto que la base será también inferior, cuando el nivel de ruido producido por la aeronave sea el mismo en uno u otro aeropuerto.

\section{Tasas municipales por licencia de apertura y control de ruidos}

En las tasas cuyo hecho imponible consiste en la prestación de servicios o la realización de actividades administrativas en régimen de derecho público que se refieran, afecten o beneficien de modo particular al obligado tributario puede concurrir un elemento ambiental, si el servicio o actividad tiene un carácter ecológico; es decir, si estos han sido establecidos con la finalidad de autorizar y controlar determinadas conductas que tienen una incidencia medioambiental. Aunque la determinación del importe de la tasa está limitada por el coste del servicio, salvo -naturalmente- que se determine por la propia ley que la establece prescindiendo de dicho límite, y ello obstaculiza notablemente la introducción de elementos extrafiscales en su estructura, no obstante, el propio hecho de que se exija el coste de dicho servicio a quien, por contaminar, lo provoca supone un cierto desincentivo a tales conductas. Aunque aceptar dicho razonamiento supone atribuir una finalidad desincentivadora a todas las tasas, en la medida en que se exigen por determinadas actividades administrativas que se refieren, afectan o benefician a determinados sujetos, mientras que por otras que se realizan en relación con otras actuaciones, que habría que entender que no se quieren desincentivar, no se exigen.

Por otra parte, dado que la limitación que supone el coste del servicio ha de entenderse referida al «rendimiento previsto para cada tasa» $»^{23} \mathrm{o}$ al impor-

\footnotetext{
${ }^{22}$ No parece justificada la exclusión de otros aeropuertos de primera categoría de la aplicación del porcentaje del recargo, cuando el nivel de ruido que sufren estos es perfectamente equiparable, al menos en determinadas fechas en las que se concentran un mayor número de vuelos, a los sometidos al recargo.

${ }^{23}$ Art. 7.3 de la Ley orgánica 87/1980, de 22 de septiembre, de Financiación de las Comunidades Autónomas. BOE núm. 236, de 1 de octubre.
} 
te que «en su conjunto» ${ }^{24}$ se exija por ella, el reparto de la recaudación global entre los beneficiarios, afectados u obligados a los que se refiere este puede realizarse de forma tal que implique una mayor carga para quien más incide en el medio ambiente y una menor carga o una exoneración para quien ajusta su conducta a pautas más respetuosas con él ${ }^{25}$.

Así sucedería en el caso de las tasas municipales que tienen como hecho imponible la prestación del servicio municipal de medición de ruidos. La Ley del Ruido ${ }^{26}$ prevé en su Disposición Adicional Sexta ${ }^{27}$, «Tasas por la prestación de servicios de inspección», la posibilidad de establecer tasas por la prestación de servicios de inspección que realicen para verificar el cumplimiento de lo dispuesto en la ley. Lo que no constituye sino un mero recordatorio de la posibilidad, recogida en el art. 20.1 de la ley reguladora de Haciendas Locales, que tienen los ayuntamientos de establecer en todo caso tasas por la «prestación de servicios públicos o la realización de actividades administrativas de competencia local que se refieran, afecten o beneficien de modo particular a los sujetos pasivos».

Como se ha señalado, la existencia misma de la tasa supone un desincentivo a la realización de las actividades generadoras de contaminación acústica que pueden dar lugar a su exacción con ocasión de la prestación del servicio de inspección. Adicionalmente, cabe articular la tasa de forma tal, que solo se exija en aquellos supuestos en los que los niveles de ruido superan los máximos permitidos por el ayuntamiento, lo que hace recaer el coste de la prestación del servicio exclusivamente sobre $\operatorname{ellos}^{28}$. Con ello el desincen-

${ }^{24}$ Art.19.2 de la Ley 8/1989, de 13 de abril, regula el régimen jurídico de las tasas y precios públicos. BOE núm. 90 , de 15 de abril.

${ }^{25}$ Calvo Verjez J.: «Las tasas...», cit. pp. 85-90.

${ }^{26}$ Ley 37/2003, de 17 de noviembre, BOE 18 noviembre 2003.

27 «De conformidad con lo previsto en el apartado 4 del artículo 20 de la Ley 39/1988, de 28 de diciembre, Reguladora de las Haciendas Locales, las Entidades Locales podrán establecer tasas por la prestación de servicios de inspección que realicen para verificar el cumplimiento de lo dispuesto en esta Ley».

${ }^{28}$ Una modalidad intermedia es la de hacer recaer el importe de la tasa en un tercero que solicita la medición al ayuntamiento si, tras ella, no puede acreditarse el incumplimiento por el denunciado de la normativa sobre ruidos. Con ello la tasa se convierte en un paradójico desincentivo de las denuncias de actividades pretendidamente contaminantes, ante el riesgo que pueden suponer de hacer frente al coste de la tasa. Así, por poner un ejemplo, en el ayuntamiento de Colindres, de acuerdo con lo establecido en el art. 4 de la ordenanza fiscal reguladora de la tasa correspondiente a la prestación del servicio municipal de «medición de ruidos y vibraciones en locales y establecimientos», es sujeto pasivo de esta «la persona natural o jurídica que insta la prestación del servicio, a este efecto se considerará que insta el servicio:

a) En el caso de inspecciones efectuada a instancia de terceros o colindantes:

1. El denunciante si tras la medición no puede acreditarse el incumplimiento por el denunciado de la normativa sobre ruidos. 
tivo desaparece para quienes emiten ruidos por debajo de los niveles que se establecen como lícitos y se concentra en quienes emiten por encima de dichos límites ${ }^{29}$. Cabe, incluso, que se cuantifique el importe de la tasa tomando como base imponible la intensidad del ruido, su mayor o menor exceso sobre los límites permitidos, lo que, en opinión de Puig Ventosa, aun siendo más complicado, conseguiría su conversión en una tasa genuinamente ambiental, al vincular su pago a la intensidad del impacto que se pretende $\operatorname{minimizar}^{30}$.

El exigir el importe de la tasa por prestación de servicios de inspección tan solo en los supuestos en los que el obligado tributario incurre en una infracción de lo dispuesto en la normativa municipal es tanto como utilizarla misma con fines exclusivos de protección medioambiental para la consecución de la erradicación de dichos comportamientos, como un tributo con fines prohibitivos o estranguladores (en la terminología alemana) que bajo la apariencia tributaria equivaldría de hecho a una medida regulatoria o sancionadora; cuando constituye el presupuesto de su exacción la identificación de la conducta infractora y de su autor, y dicha conducta puede ser sancionada como tal infracción. Algo que, en línea de principio, no resultaría aceptable,

2. El titular de la licencia del local objeto de medición en el caso de que esta acredite el incumplimiento de la normativa sobre nivel de ruidos o aislamiento acústico».

Con la circunstancia agravante de que, según dispone la letra $d$ del mismo precepto:

«Se entiende que no existe incumplimiento que genera obligación de contribuir por el denunciante, o titular de la licencia del local o establecimiento, cuando las mediciones efectuadas no señalen la superación de los límites de control de ruidos de más de un $5 \%$ sobre el valor máximo permitido».

Normativa que se atempera, no obstante, por lo previsto en el art. 6.3:

«Para el supuesto de primera denuncia cuya verificación no acredite el incumplimiento de la normativa municipal la cuota se reducirá en el $90 \%$ de la cuota señalada anteriormente».

${ }^{29}$ Así, por ejemplo, el ayuntamiento de Ibiza, en su completa Ordenanza de protección del medio ambiente y la salud frente a la contaminación acústica, en lo referente a las «tasas por control sonométrico de vehículos» regula en su artículo 29 el «pago de tasas» por este concepto:

«1. En virtud de la disposición adicional sexta de la Ley del Ruido, el Ayuntamiento podrá exigir a los titulares de vehículos el pago de tasas por inspección sonométrica.

2. Si como resultado del control sonométrico homologado, se detectara un exceso del ruido emitido sobre los niveles máximos permitidos para el vehículo, se requerirá al titular del mismo para que efectúe el pago de las tasas por control sonométrico en un plazo de quince días naturales a contar desde el día siguiente a la realización del control».

Por el contrario, por lo que se refiere a las «tasas por control sonométrico» correspondientes a la medición sonométrica en locales o instalaciones, el art. 64.2 estipula lo siguiente:

«2. En virtud de la disposición adicional sexta de la Ley del Ruido, el Ayuntamiento podrá exigir a los titulares de locales o instalaciones de cualquier tipo el pago de tasas por inspección sonométrica, independientemente del resultado del ensayo».

${ }^{30}$ Puig Ventosa I.: «Fiscalidad ambiental...». cit. p. 142. 
en opinión del profesor Zornoza ${ }^{31}$, para quien los instrumentos de naturaleza tributaria deberían emplearse de forma en cierto modo subordinada y complementaria a la regulación legal de mandatos o prohibiciones de comportamiento, como medida transitoria orientada a la reducción progresiva de la contaminación residual, es decir, no prohibida por el ordenamiento pese a su carácter indeseable. Para el profesor Herrera, utilizar el tributo para gravar conductas ilícitas sería tanto como convertir el tributo ambiental en una especie de sanción objetiva que, a su modo de ver, presentaría problemas desde el punto de vista constitucional (culpabilidad, non bis in idem) y supondría sobrecargar a la Administración tributaria con funciones para las que no está preparada ${ }^{32}$.

También las tasas municipales por licencia de apertura pueden desempeñar un papel de desincentivo de las actividades que producen contaminación acústica. «El otorgamiento de las licencias de apertura de establecimientos» aparece expresamente recogido en la letra $i$ ) del número 4 del artículo 20 del Texto Refundido de la Ley Reguladora de las Haciendas Locales ${ }^{33}$ entre los supuestos «de realización de actividades administrativas de competencia local» en los que «en particular» las entidades locales podrán establecer tasas. Aunque su importe, tal y como dispone el art. 24.2 del mismo texto legal «no podrá exceder, en su conjunto, del coste real o previsible del servicio o actividad de que se trate», el reparto de ese coste global entre los solicitantes de la licencia puede realizarse teniendo en cuenta parámetros como el carácter de la actividad desde la perspectiva de la clasificación de las actividades como inocuas, molestas, insalubres, nocivas o peligrosas. Clasificación esta en la que la incomodidad provocada por los ruidos generados por la actividad desempeña un importante papel, de acuerdo con lo dispuesto en el art. 3 del Reglamento de Actividades Molestas, Insalubres, Nocivas y Peligrosas Decreto 2414/1961, de 30 noviembre: «Serán calificadas como "molestas" las actividades que constituyan una incomodidad por los ruidos o vibraciones que produzcan o por los humos, gases, olores, nieblas, polvos en suspensión o sustancias que eliminen». Así, por ejemplo, en la vigente Ordenanza Reguladora de la Tasa por Licencia de Apertura de Establecimientos del Ayuntamiento de Alcalá de Henares, el art. 6 establece una tarifa en la que la clasificación de la actividad como molesta determina la exigencia de una cuota mayor.

${ }^{31}$ Zornoza J.: «Tributación...», cit. pp. 18 y 19.

${ }^{32}$ Herrera Molina: Op. ult. cit. p. 120.

${ }^{33}$ BOE núm. 59, de 9 de marzo; rect. BOE núm. 63, de 13 de marzo. 


\section{El ruido y el impuesto municipal sobre vehículos de tracción mecá- nica}

El Impuesto sobre Vehículos de Tracción Mecánica es definido en el art. 92 del RDLeg 2/2004, de 5 de marzo, que aprueba el texto refundido de la Ley Reguladora de las Haciendas Locales como un «tributo directo que grava la titularidad de los vehículos de esta naturaleza, aptos para circular por las vías públicas, cualesquiera que sean su clase o categoría». El tributo grava formalmente la propiedad de los vehículos como elementos patrimoniales, aunque su auténtico objeto imponible estaría constituido por el uso potencial de los vehículos y los consiguientes costes que este origina a los ayuntamientos, primando el principio de equivalencia sobre el de capacidad económica, como una suerte de tasa convertida en impuesto por razones de factibilidad $^{34}$.

El impuesto se exige con arreglo a un cuadro de tarifas regulado en el art. 95.1 del Decreto Legislativo, que está en función de la potencia y clase del vehículo. La cuota, que es fija, se determina en función de los caballos fiscales para los turismos y tractores, la carga útil para los camiones y remolques y semirremolques arrastrados por vehículos de tracción mecánica, el número de plazas en los autobuses y los centímetros cúbicos en las motoci$\operatorname{cletas}^{35}$. Dichos parámetros serían utilizados como módulos para estimar de forma objetiva la utilización del vehículo ${ }^{36}$. El art. 95.4 faculta a los ayuntamientos a incrementar las cuotas de la tarifa mediante la aplicación de un coeficiente que no podrá ser superior a $\operatorname{dos}^{37}$.

$\mathrm{El}$ art. 95.6.b del Decreto Legislativo permite a las ordenanzas fiscales «regular, sobre la cuota del impuesto, incrementada o no por la aplicación del coeficiente», «una bonificación de hasta el 75 por 100 en función de las características de los motores de los vehículos y su incidencia en el medio ambiente», que parece remitir necesariamente a otros tipos de incidencia en

\footnotetext{
${ }^{34}$ Herrera Molina P. M.: «Hacia un Impuesto ambiental sobre Vehículos de Motor (Propuesta de Directiva comunitaria e incidencia sobre las comunidades Autónomas)» en Noticias de la Unión Europea, núm. 274, 2007, p. 79.

${ }^{35}$ En la Propuesta de Directiva del Consejo, de 5 de julio de 2005, COM (2005) 261 final, sobre los impuestos aplicables a los automóviles de turismo, se plantea una reforma de los impuestos anuales de circulación que estructure el gravamen en función de sus emisiones de $\mathrm{CO}_{2}$. Sobre dicha propuesta, Herrera Molina P. M.: «Hacia un Impuesto...», cit. pp. 73-79. López Espafador C.: «La protección del medio ambiente y el impuesto sobre vehículos de tracción mecánica» en Nueva Fiscalidad, núm.1/2007, pp. 60-74 y «El impuesto sobre Vehículos de tracción Mecánica en el panorama de la armonización físcal comunitaria» en Noticias de la Unión Europea, núm. 273, 2007, pp. 73-76.

${ }^{36}$ Herrera Molina P. M.: op. ult. cit. loc. cit.

${ }^{37}$ A favor de una reorientación más decidida hacia fines ambientales de este tributo se muestra Herrera Molina P. M.: «El principio...», cit. p. 205 y «Hacia un Impuesto ...», cit. p. 79.
} 
el medio ambiente distintos a los provocados por las emisiones de gases contaminantes, puesto que en la letra $a$ ) del mismo artículo, se prevé la posibilidad de establecer otra bonificación, que pretende servir también a una finalidad ecológica, en función del resultado contaminante de la combustión del carburante que consuma el vehículo: «de hasta el 75 por 100 en función de la clase de carburante que consuma el vehículo, en razón de la incidencia de la combustión de dicho carburante en el medio ambiente». Cabría perfectamente articular dicha bonificación, cuya regulación en sus restantes aspectos sustantivos y formales se remite a las ordenanzas fiscales, en función de la incidencia en el medio ambiente provocada por la contaminación acústica emitida por el vehículo.

La Directiva 1981/334/CEE, de 13 de abril, que «adapta al progreso técnico la Directiva 70/157/CEE del Consejo, relativa a la aproximación de las legislaciones de los Estados miembros sobre el nivel sonoro admisible y el dispositivo de escape de los vehículos a motor ${ }^{38}$, establece unos límites máximos, expresados en decibelios, a los niveles sonoros para cada tipo de vehículo, en función de los parámetros especificados en el Anexo I, $1.1^{39}$, prescribiendo que «el vehículo, su motor y los silenciosos de escape y de admisión deberán diseñarse, construirse y montarse de tal modo que, en condiciones normales de utilización y a pesar de que puedan estar sometidos a vibraciones, el vehículo pueda satisfacer las prescripciones de la presente Directiva». Los «valores límite» son establecidos en el 5.2.2.1. del Anexo $\mathrm{I}^{40}$.

${ }^{38}$ DOL 18 de mayo de 1981, núm.131.

${ }^{39} \mathrm{La}$ forma o los materiales de la carrocería (en particular, el compartimiento motor y su insonorización); la longitud y anchura del vehículo; el tipo de motor (dos o cuatro tiempos, de pistón alternativo o rotativo, número y volumen de cilindros, número y tipo de carburadores o sistemas de inyección, distribución de las válvulas, potencia máxima y régimen de giro correspondiente [S]); el sistema de transmisión, en particular, el número de velocidades y su desmultiplicación; el número, tipo y emplazamiento de los silenciosos de escape; y el número, tipo y emplazamiento de los silenciosos de admisión.

40 «5.2.2.1.1. (...) Vehículos destinados al transporte de personas, cuyo número de asientos no exceda de nueve, incluido el correspondiente conductor (...) 80

5.2.2.1.2. (...) Vehículos destinados al transporte de personas, cuyo número de asientos sea superior a nueve, incluido el correspondiente conductor, y cuyo peso máximo autorizado no exceda de 3,5 toneladas (...) 81

5.2.2.1.3. (...) Vehículos destinados al transporte de mercancías, cuyo peso máximo autorizado no exceda de 3,5 toneladas (...) 81

5.2.2.1.4. (...) Vehículos destinados al transporte de personas, cuyo número de asientos sea superior a nueve, incluido el correspondiente al conductor, y cuyo peso máximo autorizado exceda de 3,5 toneladas (...) 82

5.2.2.1.5. (...) Vehículos destinados al transporte de mercancías, cuyo peso máximo autorizado exceda de 3,5 toneladas (...) 86

5.2.2.1.6. (...) Vehículos destinados al transporte de personas, cuyo número de asientos exceda de nueve, incluido el correspondiente al conductor, y cuyo motor tenga una potencia igual o superior a $147 \mathrm{~kW}($...) 85 
El Anexo III de la Directiva recoge el «anexo al certificado de homologación CEE de un tipo de vehículo en lo que respecta al nivel sonoro», en el que ha de constar tanto el «nivel sonoro del vehículo en marcha» como el «nivel sonoro del vehículo parado», determinados de acuerdo con las especificaciones de la directiva.

Podría sin dificultad, de manera similar a la establecida en la tasa de aterrizaje para las aeronaves, establecerse una clasificación acústica de los vehículos en función de la diferencia entre los niveles sonoros del vehículo contenidos en el certificado de homologación CEE y los máximos fijados en la Directiva; clasificación que permitiría graduar el porcentaje de la bonificación en función de esta: excluyendo a los vehículos más ruidosos y atribuyendo una bonificación superior a aquellos cuyos niveles sonoros sean más bajos en relación con dicho límite.

Aunque el impuesto no vaya a dejar de recaer sobre la capacidad económica del sujeto pasivo, a través de índices indirectos recogidos en la tarifa ${ }^{41}$, el hecho de que la bonificación pueda llegar a alcanzar un $75 \%$ y quepa la posibilidad de graduarla de acuerdo con la incidencia en el medio ambiente de cada vehículo, pueden transformar de hecho la naturaleza del impuesto y convertirlo, al menos en sus tres cuartas partes, en un gravamen en función de la contaminación acústica. La Comisión Europea, en su Libro verde sobre «Futura política sobre el ruido» del año 1996, señaló que «en el contexto de la actual revisión de la imposición sobre los vehículos, una mayor diferenciación en los actuales impuestos anuales sobre los vehículos y los impuestos sobre los combustibles que tenga en cuenta los costes derivados del ruido podría ser un instrumento efectivo». También el profesor Herrera subraya que, a diferencia de la contaminación correspondiente a las emisiones de $\mathrm{CO}_{2}$, que constituye un fenómeno global que debe ser afrontado con medidas de carácter supranacional, «otros fenómenos contaminantes ligados a los vehículos (partículas, ruido, residuos) sí presentan un impacto local que justifica una participación de los municipios en el impuesto que las grave» ${ }^{42}$.

La bonificación prevista en la letra $b$ ) podría compaginarse con la autorizada en la letra a) del mismo artículo ${ }^{43}$ : «bonificación de hasta el 75 por 100 en función de la clase de carburante que consuma el vehículo, en razón

5.2.2.1.7. (...) Vehículos destinados al transporte de mercancías cuyo motor tenga una potencia igual o superior a $147 \mathrm{~kW}$ y cuyo peso máximo autorizado exceda de 12 toneladas (...) $88 »$.

${ }^{41}$ Tal y como señala López Espafador, «bien es cierto que a más potencia suele existir una mayor capacidad contaminante del vehículo, pero no tiene por qué darse una correlación exacta entre tales circunstancias». «El impuesto...», cit. p. 70.

${ }^{42}$ Herrera Molina P. M.: «Hacia un impuesto...», cit. p. 74.

${ }^{43}$ Sobre estas bonificaciones Herrera Molina P. M.: «Hacia un impuesto...», cit. pp. 7980. Estafador C. M.: «La protección...», cit. pp. 58-60 y «El impuesto...», cit. pp. 72-73. 
de la incidencia de la combustión de dicho carburante en el medio ambiente», podría incluso tenerse en cuenta la «incidencia de la combustión» de cada tipo de carburante en el medio ambiente en términos de contaminación acústica; lo que podría hacer que, en determinados casos en los que ambas fueran aplicables, no pudiera hacerse efectivo el importe de bonificación de ambas por sumar sus porcentajes una cantidad superior al 100\%; lo que les haría perder parte de su efectividad respectiva como incentivo. Lo que no es sino una muestra de la indefinición, denunciada por el profesor Herrera, de algunos supuestos de bonificación previstos por la Ley de Haciendas Locales que, junto con el hecho de que su coste recaiga íntegramente sobre las arcas municipales, ha hecho que las ordenanzas municipales hayan incorporado dichos beneficios de forma muy moderada ${ }^{44}$.

\section{Un eventual recargo autonómico sobre el impuesto estatal especial sobre determinados medios de transporte y el ruido}

El art.12 de la LO 8/1980, de 22 de septiembre, de Financiación de las Comunidades Autónomas ${ }^{45}$, autoriza a estas a «establecer recargos sobre los tributos del Estado susceptibles de cesión, excepto en el Impuesto sobre Ventas Minoristas de Determinados Hidrocarburos. En el impuesto sobre el Valor Añadido e Impuestos Especiales únicamente podrán establecer recargos cuando tengan competencias normativas en materia de tipos de gravamen». El art. 43 de la Ley 21/2001, que regula las Medidas Fiscales y Administrativas del Nuevo Sistema de Financiación de las Comunidades Autónomas de Régimen Común y Ciudades con Estatuto de Autonomía ${ }^{46}$, prevé la cesión a las comunidades autónomas de competencias normativas en el Impuesto Especial sobre Determinados Medios de Transporte, concretamente la posibilidad de «incrementar los tipos de gravamen aplicables a los epígrafes del apartado 1 del artículo 70 de la Ley 38/1992, de 28 de diciembre, de Impuestos especiales, en un 15 por 100 como máximo»; por lo tanto, cabría establecerse recargos autonómicos sobre dicho impuesto estatal, siempre que se respetase lo dispuesto en el art. 12.2 de la LOFCA: «no podrán configurarse de forma que puedan suponer una minoración en los ingresos del Estado por dichos impuestos, ni desvirtuar la naturaleza o estructura de los mismos».

${ }^{44}$ Herrera Molina P. H.: «El principio...», cit. p. 205, quien denuncia también el uso abusivo de dichos beneficios ambientales previstos para el impuesto de circulación, con la finalidad de atraer a su jurisdicción empresas de alquiler de vehículos. «La protección...» cit. pp. 58-60 y «El impuesto...» cit. pp. 72-73.

${ }^{45}$ BOE núm. 236, de 1 de octubre.

${ }^{46}$ BOE núm. 313, de 31 de diciembre. Rect. BOE núm. 122, de 22 de mayo de 2002. 
La naturaleza del Impuesto Especial de Determinados Medios de Transporte es la de un impuesto indirecto que grava el consumo de dichos bienes como capacidad económica que manifiesta quien realiza la primera matriculación en España de un vehículo de motor, embarcación o aeronave; capacidad económica que el art. 69 de la Ley 38/1992 $2^{47}$, que regula la base imponible del impuesto, cuantifica para los medios de transporte en el «importe que con ocasión de la adquisición del medio de transporte se haya determinado como base imponible a efectos del Impuesto sobre el Valor Añadido, de un impuesto equivalente $o$, a falta de ambos, por el importe total de la contraprestación satisfecha por el adquirente»y, para los usados «por su valor de mercado en la fecha de devengo del impuesto».

El que el art. 70 de la ley establezca una tarifa en la que los tipos de gravamen varían en función de la clasificación de los vehículos según sus emisiones oficiales de $\mathrm{CO}_{2}$ no convierte realmente, en mi opinión, el impuesto en un gravamen de dichas emisiones. El impuesto recae sobre la capacidad económica del consumo, que es la que cuantifica su base imponible ${ }^{48}$. Así ha tenido ocasión de declararlo el TC en su STC 137/2003, «a la vista de la definición legal del hecho imponible, estamos en presencia de un impuesto sobre el consumo o sobre la adquisición del bien por el consumidor final, pues se trata de un tributo de naturaleza indirecta que recae sobre consumos específicos (...). En consecuencia, el gravamen del tributo en cuestión se determina en función de la capacidad económica exteriorizada con la adquisición de un medio de transporte, de manera que con ello se hace evidente que su verdadero fin consiste en gravar la capacidad contributiva manifestada por el consumo de una renta». Puede considerarse el tipo 0, que se fija para el primer epígrafe de la tarifa, como una exención a favor de los vehículos menos contaminantes y los tipos diferenciados para los epígrafes $2 .^{\circ}$, $3 .^{\circ}$ y $4 .^{\circ}$ como meras bonificaciones o meros recargos -según cuál sea el que se quiera tomar como tipo impositivo de referencia-, establecidos en función de las emisiones de $\mathrm{CO}_{2}$ del vehículo ${ }^{49}$.

${ }^{47}$ Ley de 28 de diciembre, que regula los Impuestos Especiales, BOE núm. 312, de 29 de diciembre, rect. BOE núm. 16, de 19 de enero.

${ }^{48}$ Como afirma Borrero, «La articulación de la base imponible de acuerdo con las directrices del IVA (...) parecen configurar la estructura cuantitativa del IEDMT de acuerdo, básicamente, con las exigencias del principio de capacidad económica y, en general, el tributo de acuerdo con una finalidad meramente recaudatoria; en todo caso, alejada de las exigencias del principio 'quien contamina paga'». Borrero Moro C. J., Borrero Moro C.: «Un sueño frustrado (La tributación estatal pretendidamente ambiental sobre la energía» en Quincena Fiscal núms. 3-4/2007, p. 64. En opinión de Herrera Molina P. M.: «El principio...», cit. p. 203. «Desde el punto de vista técnico la solución no es la ideal -tendría más sentido que la base imponible estuviera constituida por las emisiones y no por el precio del vehículo».

${ }^{49}$ Hermosilla Martín R. y Rubio Escobar P. M. consideran que «tras dicha reforma del Impuesto Especial sobre determinados medios de transporte resulta imposible negar la clara vocación medioambiental que se ha dado definitivamente a este tributo, si bien, según 
Tal y como afirma el profesor Zornoza «de los tributos ambientales y relacionados con el medio ambiente, han de separarse aquellos otros que, careciendo de cualquier relación con el tipo de problemas que nos interesan, son capaces de albergar medidas desgravatorias de diversa naturaleza (reducciones en base, tipos de gravamen bonificados, deducciones en cuota, etc.) que pretendan fomentar determinados comportamientos de protección del medio ambiente ${ }^{50}$. Aunque, por otro lado, como señala la exposición de motivos de la Ley 38/1992, «la creación de este impuesto deriva, inicialmente, de la propia armonización del Impuesto sobre el Valor Añadido que impone la supresión de los tipos incrementados hasta ahora existentes. La sujeción de determinados vehículos y medios de transporte a dicho tipo incrementado, no respondía exclusivamente al gravamen de la capacidad contributiva puesta de manifiesto en su adquisición, sino a la consideración adicional de las implicaciones de su uso en la producción de costes sociales específicos en el ámbito de la sanidad, las infraestructuras o el medio ambiente».

Considero viable el establecimiento de un recargo autonómico sobre el impuesto estatal que discriminara en función de la incidencia en el medio ambiente constituida por la contaminación acústica del vehículo. Aunque el modelo de recargo autonómico que se ha adoptado hasta el momento es el recargo sobre las cuotas, en realidad ni la CE ni la LOFCA precisan si el recargo ha de ser sobre la base o la cuota, por lo que no debería haber inconveniente en admitir ambas modalidades ${ }^{51}$. La existencia de recargos autonómicos sobre la denominada tasa sobre el juego que consisten en una cuota fija sería buena prueba de ello, pues podrían ser considerados tanto recargos sobre la base como sobre la cuota. De hecho, en un tributo en el que la tarifa se establece en función de las emisiones de $\mathrm{CO}_{2}$ del vehículo, tendría más sentido establecer un recargo directamente sobre la base para desincentivar la contaminación acústica que condicionar el importe del mismo a la mayor o menor emisión de $\mathrm{CO}_{2}$ por parte del vehículo.

En cuanto a los límites establecidos por el art.12.2 de la LOFCA, por lo que se refiere al primero, no se producirá más que en el supuesto de que el

nuestro criterio, y en la medida en que su materia imponible no se ha visto modificada, dificilmente puede afirmarse que este impuesto grave ahora, estrictamente, la 'capacidad de contaminar', sino la capacidad económica o riqueza exteriorizada por el sujeto pasivo como consecuencia de la primera matriculación en España de un vehículo provisto de vehículo a motor». «La tributación medioambiental y los medios de transporte» en Bécker F. et al. Cit. p. 744.

${ }^{50}$ Zornoza Pérez J. J.: «Tributación...», cit. p. 20.

${ }^{51}$ Ruiz de Velasco Puntín C.: «Presente y futuro de los recargos autonómicos» en Nueva Fiscalidad núm. 4. 2008, p. 38. Calvo Vergez. J., p. 64. «El papel de los recargos sobre impuestos estatales en la financiación de las Comunidades autónomas. ¿Una vía olvidada?» en Nueva Fiscalidad, núm. 8/2006, p. 64. 
recargo sea configurado como un gasto deducible de la base, una deducción en la cuota o un pago a cuenta del impuesto estatal, al margen de que una vez que el tributo está íntegramente cedido a la CA no quepa minoración real alguna de los ingresos del Estado. Por lo que se refiere al segundo, la prohibición de desvirtuar la naturaleza o estructura del impuesto ${ }^{52}$, en la medida en que la base imponible seguiría siendo en todo caso determinada de la misma forma y el impuesto estatal continuaría recayendo sobre el consumo de estos bienes en función de las emisiones de $\mathrm{CO}_{2}$ del vehículo, no se violentaría esta prohibición. Dado que el recargo se superpone o añade al tributo estatal, difícilmente podría desvirtuar su estructura si no produce una alteración en la definición de su hecho imponible, los sujetos pasivos, la base imponible o los restantes elementos que configuran la relación jurídico-tributaria de dicho impuesto ${ }^{53}$.

En realidad, un recargo autonómico sobre la base del impuesto, si el recargo responde a una finalidad distinta que los tipos de gravamen estatales, como sería el caso, a mi modo de ver, respeta mejor la naturaleza y estructura del impuesto estatal que un recargo sobre su cuota, dado que no «modula» el gravamen determinado por el legislador estatal en la tarifa del impuesto en función de parámetros distintos a los elegidos por este. En opinión de López Espafador, desde la perspectiva de la justicia tributaria, es más adecuado que el gravamen tenga en consideración la capacidad contaminante del vehículo a través de la aplicación de diferentes tipos de gravamen, sin perjuicio de que la base imponible se determine en función del precio del vehículo, tomando así en consideración un índice indirecto de capacidad económica que funcionaría como ponderación o complemento de la utilización del tributo con una finalidad de protección del medio ambiente ${ }^{54}$. Por otra parte, solo cuando el recargo, como es el caso, se establece en función de un parámetro distinto al elegido por la tarifa del impuesto estatal, tendría realmente sentido su establecimiento, dado que esta posibilidad está condicionada a la cesión de competencias normativas en materia de tipos de gravamen, lo que haría innecesaria la utilización del recargo con la única finalidad de incrementar los tipos estatales.

No obstante, si se considera inadecuado el hacer variar el importe del recargo en función de un parámetro distinto a la contaminación acústica del vehículo, siempre podría articularse como una tarifa de tipos graduales establecidos en función de dicha contaminación. Tal y como afirma Calvo Vergez, «la comunidad autónoma tiene plena libertad para diseñar el paráme-

${ }^{52}$ Sobre las diversas interpretaciones de esta prohibición Nieto Montero, J. J.: «Los recargos autonómicos sobre tributos estatales», Revista de Información Fiscal, núm. 35. 1999. p. 95.

${ }^{53}$ En este sentido Ruiz de Velasco Puntín C.: «Presente...», cit. pp. 57-58 y Calvo Vergez. J.: «El papel...», cit. p. 105.

${ }^{54}$ López Espafador C.: «La protección...», cit. p. 74. y «El impuesto...», cit. p. 76. 
tro de aplicación del recargo así como su tipo de gravamen (...) tanto si el recargo se establece sobre las bases imponibles o liquidables del tributo principal como si se establece sobre las cuotas íntegras, líquidas o cualquier otra de dicho tributo $»^{55}$.

En definitiva, las comunidades autónomas podrían establecer un recargo variable en función de la clasificación acústica de los vehículos, de forma similar a la que se ha señalado en relación con la bonificación en el impuesto local sobre vehículos de tracción mecánica: estableciendo una clasificación acústica de los vehículos en función de la diferencia entre los niveles sonoros del vehículo contenidos en el certificado de homologación CEE y los niveles máximos fijados en la Directiva, y graduando el recargo en función de esta: excluyendo a los vehículos menos ruidosos y atribuyendo un recargo superior a aquellos cuyos niveles sonoros sean más altos en relación con dicho límite ${ }^{56}$.

Otra posibilidad, apuntada por Lafont Sendino, sería la de utilizar directamente la cesión de competencias normativas en materia de tipos de gravamen «teniendo en cuenta las características técnicas de los vehículos y gravando más a los más contaminantes (...) incluso por emisiones acústicas $»^{57}$. A mi modo de ver, esta entraría en contradicción con el tenor literal del citado art. 43 de la ley 21/2001, que exige el mantenimiento de los epígrafes del apartado 1 del art. 70 de la Ley de Impuestos Especiales -actualmente establecidos en función de las emisiones de $\mathrm{CO}_{2}$ y no en función de la contaminación acústica- y tan solo prevé la posibilidad de «incrementar los tipos de gravamen aplicables», lo que, siempre a mi juicio, impediría cambiar los actuales tipos porcentuales por unos específicos o graduales fijados en función de la mayor o menor contaminación acústica. Lo único que permite el precepto es incrementar -con el límite del 15\% - las actuales alícuotas aplicables a cada epígrafe; incrementarlas, en función de la contaminación acústica, solo para unos vehículos y para otros no sería equivalente a una modificación de los actuales epígrafes de acuerdo con este criterio.

\section{La imposición sobre los hidrocarburos y el ruido}

El Impuesto sobre las Ventas Minoristas de Determinados Hidrocarburos es un tributo de naturaleza indirecta que recae sobre el consumo de aquellos,

\footnotetext{
${ }^{55}$ Calvo Vergez J.: «El papel...», cit. p. 73.

${ }^{56}$ En opinión de Borrero, «el impuesto se presenta como una potencial herramienta jurídica para, por un lado, imputar los distintos costes sociales (...) susceptibles de generar los distintos medios de transporte; $y$, por el otro, modular el consumo de los medios de transporte en términos ambientales». Borrero Moro C.: «Un sueño...», cit. p. 58.

${ }^{57}$ Lafont Sendino S.: «Perspectivas futuras de la fiscalidad ambiental en Galicia. Propuesta de nuevas figuras tributarias» en Noticias de la Unión Europea, núm. 274, 2007, p. 102.
} 
gravando en fase única las ventas minoristas de los productos comprendidos en su ámbito objetivo. Fue creado por la Ley 24/2001, de 27 de diciembre, de Medidas Fiscales, Administrativas y del Orden Social ${ }^{58}$ y cedido íntegramente a las comunidades autónomas, según dispone el art. 36 de la Ley $21 / 2001$, de 27 de diciembre, que regula las medidas fiscales y administrativas del nuevo sistema de financiación de las comunidades autónomas de régimen común y ciudades con Estatuto de autonomía ${ }^{59}$. La Ley 24/2001, en el número $10 \mathrm{del}$ art. 9 regula el tipo de gravamen, que «se formará mediante la suma de los tipos estatal y autonómico», el estatal es, por lo que nos interesa, de $24 € / 1000$ litros, tanto para las gasolinas como para los gasóleos de uso general. El autonómico será el que establezca la respectiva comunidad autónoma de conformidad con lo regulado en el art. 44 de la misma ley. Las comunidades autónomas que han hecho uso de sus competencias normativas, de discriminar entre el gravamen correspondiente a las gasolinas y el correspondiente al gasóleo, lo han hecho a favor de este.

Dado que Ley 24/2001 establece en el número 3 de su art. 9 que «los rendimientos que se deriven del presente Impuesto quedarán afectados en su totalidad a la financiación de gastos de naturaleza sanitaria orientados por criterios objetivos fijados en el ámbito nacional. No obstante lo anterior, la parte de los recursos derivados de los tipos de gravamen autonómicos podrá dedicarse a financiar actuaciones medioambientales que también deberán orientarse por idéntico tipo de criterios», podría resultar adecuado que las CC. AA. utilizaran sus competencias normativas para discriminar el gravamen en función del daño medioambiental ocasionado por el ruido respectivo producido por los vehículos que utilizan gasolina y gasóleo, daño que, desde la perspectiva del ruido, es mayor en los vehículos con motores diésel ${ }^{60}$. Como se ha señalado antes, la Comisión Europea, en su Libro verde sobre «Futura política sobre el ruido» del año 1996, consideró que una mayor diferenciación en los impuestos sobre los combustibles que tenga en cuenta los costes derivados del ruido podría ser utilizada como un instrumento para la lucha contra esta contaminación.

${ }^{58}$ BOE núm. 313, de 31 de diciembre, rect. BOE núm. 124, de 24 de mayo.

${ }^{59}$ BOE 31 diciembre 2001, núm. 313; rect. BOE 22 mayo 2002, núm. 122.

${ }^{60}$ En contra de la atribución de una finalidad medioambiental a este impuesto se pronuncia Patón, para quien el consumo de los hidrocarburos gravados por el impuesto no desincentivaría su consumo "pues este consumo es insensible a los cambios de precio en tanto que no existe un alternativa viable y más económica. Así pues, la protección medioambiental constituye en este impuesto una mera excusa en la búsqueda de una mayor recaudación tributaria». Patón García, G.: «Hacia un modelo de impuesto ambiental: las reformas pactadas y la creación de nuevos tributos», en Nueva Fiscalidad; núm. 7/2006, pp. $48-49$. 
La misma consideración cabe hacer con respecto al Impuesto sobre Hidrocarburos, en la Ley 38/1992, de 28 de diciembre, que regula los impuestos especiales ${ }^{61}$. Dicho impuesto es indirecto, real, objetivo, monofásico, instantáneo y de finalidad extrafiscal. Borrero Moro pone de manifiesto cómo el consumo de productos energéticos produce una contaminación atmosférica, que pone en relación con los efectos negativos del ruido y la degeneración del paisaje. El Impuesto Especial sobre Hidrocarburos se configura como un impuesto encaminado a redistribuir los costes ambientales entre sus provocadores, al tiempo que trata de proteger el medio ambiente, modulando comportamientos a través del desincentivo del consumo de hidrocarburos ${ }^{62}$.

Por lo que se refiere a lo relativo a la contaminación acústica, lo cierto es que en las tarifas reguladas en su art. 50, el impuesto establece tipos específicos sensiblemente inferiores para los gasóleos a los establecidos para las gasolinas. Tal y como ha puesto de manifiesto la Comisión Europea «según los criterios utilizados para analizar el impacto ambiental (emisiones de gases, emisiones de partículas, ruido), no existirían motivos para aplicar impuestos diferentes al diésel y a la gasolina consumidos por los vehículos para pasajeros. Un equilibrio razonable conduciría a una fiscalidad global equivalente» ${ }^{63}$. Tal y como señala Borrero, dicha diferencia se sostendría, no tanto en las exigencias del principio «quien contamina paga», como en la protección de determinados sectores económicos, así como en la menor capacidad económica que, en términos generales, denota el uso de un producto energético en el marco de actividades económicas, respecto de su uso en el marco de actividades particulares ${ }^{64}$.

No obstante, en relación con la utilización de los impuestos especiales con una finalidad ecológica, conviene tener presentes las dudas expresadas por Vaquera García, atendiendo a la escasa vinculación del fin medioambiental con el método de medición de la base imponible y a «la reducida o prácticamente nula concienciación ambiental a que llevaría una elevación de la cuantía de tales tributos, puesto que la inflexibilidad de su demanda, la lógica reacción de la opinión pública y la difícil justificación del incremento en la carga fiscal si se emplean esas magnitudes de medición, llevarían a que se diluyese la función extrafiscal en el componente recaudatorio, por lo que no se alcanzaría el efecto perseguido de limitar la producción de daños a la

${ }^{61}$ BOE núm. 312, de 29 de diciembre.

${ }^{62}$ Borrero Moro C.: «Un sueño...», cit. p. 52.

${ }^{63}$ Propuesta de Directiva del Consejo por la que se modifican la Directiva 92/81/CEE y la Directiva 92/82/CEE con vistas a establecer un régimen fiscal especial para el gasóleo utilizado como carburante con fines profesionales y aproximar los impuestos especiales de la gasolina y del gasóleo. COM (2002) 410 final. Bruselas, 24.7.2002. El subrayado es mío.

${ }^{64}$ Borrero Moro C.: «Un sueño...», cit. pp. 41-42. 
naturaleza» ${ }^{65}$. Aunque, en línea de futuro y en relación específicamente con la contaminación acústica, cabe pensar en que, una vez se introduzcan en el mercado vehículos eléctricos, el gravamen de los hidrocarburos sí que podría constituir un elemento determinante en la configuración de una demanda que dejaría de ser inelástica al existir un bien sustitutivo, primando la utilización de los motores eléctricos que no los consumen, notablemente menos ruidosos que los de explosión.

\section{El impuesto sobre el daño medioambiental causado por la instala- ción de transportes por cable de la Comunidad Autónoma de Ara- gón y el paisaje}

El impuesto medioambiental aragonés sobre el daño causado por la instalación de transportes por cable es el que de forma más explícita proclama como su objeto ${ }^{66}$ «la concreta capacidad económica que se manifiesta en determinadas actividades desarrolladas mediante la utilización de las instalaciones o elementos de dichos sistemas de transporte de personas, mercancías y bienes, como consecuencia de su incidencia negativa en el entorno natural, territorial y paisajístico de la Comunidad Autónoma de Aragón».

Dicho impuesto fue establecido por la Ley 13/2005, de 30 de diciembre, de Medidas Fiscales y Administrativas en materia de Tributos Cedidos y Tributos Propios de la Comunidad Autónoma de Aragón ${ }^{67}$, en cuyo Preámbulo se hace referencia a que el empleo en la actividad empresarial de transportes mediante líneas o tendidos de cable «es, en primer lugar, un elemento perturbador del paisaje»y a que el impuesto grava «el perjuicio en el medio ambiente y en otros valores superiores (territorio, paisaje, flora, fauna) que deben ser protegidos y, en su caso, restaurados». De forma congruente, tal y como también señala el preámbulo, «dicho daño se entiende producido aun cuando dichas instalaciones se encontraran en desuso o no hubieran entrado en funcionamiento», lo que parece apuntar de forma inequívoca al daño

65 Vaquera García, A.: Fiscalidad y medio ambiente, Lex Nova, Valladolid. 1999. pp. 308-309. También para Borrero no se podría «dejar de reconocer la existencia de razones, fundamentalmente, recaudatorias en la justificación de su establecimiento y conservación dentro del ordenamiento jurídico español». Borrero Moro C.: «Un sueño...», cit. p. 37 , no obstante, en relación con la inelasticidad de la demanda, este autor (p. 42) subraya el hecho de que «en aquellas actividades relacionadas con el tiempo libre, (...) la demanda es más elástica; además de que los costes sociales originados tienen una justificación escasamente solidaria».

${ }^{66}$ Objeto-fin del tributo para la profesora Soler Roch, M. T.: «El principio de capacidad económica y la tributación medioambiental» en Bécker, F. et al., Tratado..., cit. p. 93.

${ }^{67}$ BO. Aragón 31 diciembre 2005, núm. 154; rect. BO. Aragón 8 marzo 2006, núm. 28. 
en el paisaje, puesto que es realmente difícil pensar en otro tipo de daños ambientales distintos a este cuando las instalaciones no están en funcionamiento ${ }^{68}$. En opinión del profesor Rosembuj, el impuesto aragonés confundiría «custodia territorial con territorialización ambiental. La actividad es dañosa y por tanto susceptible de prohibición, de indemnización por daños y perjuicios o, de gravamen sobre su contenido. Pero, no hay ni seña de protección del bien ambiental. La referencia al paisaje no se refleja en el impuesto, sino incidentalmente» ${ }^{69}$.

Adicionalmente, el art. 12.2 del vigente Texto Refundido de la Legislación sobre los impuestos medioambientales de la Comunidad Autónoma de Aragón, Decreto Legislativo 1/2007, de 18 septiembre, establece que «en el caso de instalaciones o elementos del transporte mediante líneas o tendidos de cable que se encontraran en situación de desuso durante, al menos, tres años, la cuota tributaria será la que resulte de multiplicar por tres la que hubiere correspondido en función del número y longitud de las citadas instalaciones o elementos de transporte»; lo que, de forma un tanto paradójica a mi modo de ver, implica que se triplica el gravamen en un supuesto en el que el único daño medioambiental producido por las instalaciones es el paisajístico. La justificación del precepto podría estar en el establecimiento de una especial protección del paisaje mediante un desincentivo superior de dicho daño en el medio ambiente que pretende en última instancia su cesación mediante la retirada de las instalaciones. De hecho, el art. 35 del texto refundido establece una deducción en la cuota íntegra de cada impuesto, «hasta el límite del 30 por 100 de su importe, por la realización de inversiones en bienes o derechos del inmovilizado material o inmaterial, situados o destinados dentro del ámbito de aplicación del impuesto, y dirigidas a la adopción de medidas preventivas, correctoras o restauradoras de los efectos negativos de la contaminación en el medio natural y territorial de la Comunidad Autónoma de Aragón», por importe «del 20 por 100 del precio de adquisición o coste de producción de las inversiones efectivamente realiza-

${ }^{68}$ Art. 9.2 del Texto Refundido de la Legislación sobre los impuestos medioambientales de la Comunidad Autónoma de Aragón, Decreto Legislativo 1/2007, de 18 septiembre. BO. Aragón 3 octubre 2007, núm. 117. «1. Constituye el hecho imponible del impuesto el daño medioambiental causado directamente por las instalaciones de transporte mediante líneas o tendidos de cable, que se relacionan en el artículo 7. (...)». Para de la Hucha Celador F.: «El poder tributario de las Comunidades Autónomas en materia medioambiental» en Bécker F. et al., Tratado..., cit. en estos supuestos «aun admitiendo a efectos dialécticos la producción del mencionado daño», la capacidad económica que se pretendería gravar sería desconocida, p. 323.

«2. Se entenderá producido el daño medioambiental aun cuando las instalaciones y elementos del transporte descrito se encuentren en desuso o no hayan entrado en funcionamiento».

${ }^{69}$ Rosembuj T.: «Los impuestos ambientales...», cit. p. 14. 
das por inversiones destinadas a la protección del medio ambiente». Pues bien, según dispone el art. 24 del Reglamento de Desarrollo Parcial de la Ley 13/2005, de 30 de diciembre de 2005, de Medidas Fiscales y Administrativas en Materia de Tributos Cedidos y Tributos Propios de la Comunidad Autónoma de Aragón, para la aplicación de los Impuestos Medioambientales ${ }^{70}$ «se entenderá que van destinadas a la adopción de tales medidas, entre otras, las siguientes inversiones:

a) En el Impuesto sobre el daño medioambiental causado por la instalación de transportes por cable, las destinadas a la restauración del medio natural afectado por la retirada de las instalaciones en uso o en desuso $»^{71}$.

Según el preámbulo, en el impuesto aragonés se habría «utilizado una unidad contaminante de medida del daño medioambiental acorde y coherente con ese perjuicio, como son el número y la longitud de las instalaciones de transporte por cable». En el art. 11 del vigente texto refundido se define la base imponible del impuesto a las «unidades contaminantes de medida del daño medioambiental» constituidas por «el número y longitud de las instalaciones de transporte por cable de personas» $y$ «el número y longitud de las instalaciones de transporte por cable de mercancías o materiales». La cuota tributaria, según ordena el art. 12 del mismo texto, se obtiene de aplicar a la base imponible unos tipos de gravamen, entre los que resaltaría los siguientes:

«1. ${ }^{\circ}$ Transporte de personas en las instalaciones de teleféricos y remonta-pendientes:

c) Por cada metro de longitud del transporte por cable de personas: 12 euros.

(...)

2. ${ }^{\circ}$ Transporte de mercancías o materiales en las instalaciones de remonte utilizadas en el medio forestal. Por cada metro de longitud del transporte por cable de mercancías: 10 euros», en cuanto que, en mi opinión, los metros de longitud del transporte de personas o de mercancías y materiales de ser una medida «acorde y coherente» del daño medioambiental, lo serían únicamente del daño en el paisaje.

Cabe poner en relación el impuesto aragonés con el Impuesto extremeño sobre Instalaciones que incidan en el Medio Ambiente, actualmente regulado en el Decreto Legislativo 2/2006, de 12 diciembre, que aprueba el Texto Refundido de las disposiciones legales de la Comunidad Autónoma de

${ }^{70}$ BO. Aragón 20 enero 2007, núm. 8.

${ }^{71}$ Sobre la importancia que el examen de las técnicas desgravatorias tiene para la determinación de la finalidad y naturaleza de los tributos extrafiscales, Ruiz Almendral, V. y Zornoza Pérez J.: «El impuesto sobre grandes...», cit. p. 25 y ss. y Zonoza Pérez J.: «El impuesto sobre determinadas actividades que inciden en el medio ambiente: finalidad extrafiscal y límites al poder tributario de las Comunidades Autónomas» en Noticias de la Unión Europea, núm. 281, 2008, pp. 71-72. 
Extremadura en materia de Tributos Propios ${ }^{72}$. Aunque no se haga en su normativa reguladora referencia expresa alguna al paisaje como objeto del daño medioambiental ${ }^{73}$, al limitarse el art. 12 del texto refundido a señalar en lo referente a la naturaleza y objeto del impuesto que este «grava la incidencia, alteración o riesgo de deterioro que sobre el medio ambiente de la Comunidad Autónoma de Extremadura ocasiona la realización de las actividades a que se refiere esta ley, a través de las instalaciones y demás elementos patrimoniales afectos a las mismas, con el fin de contribuir a compensar a la sociedad el coste que soporta y a frenar el deterioro del entorno natural», quizás pudiera entenderse que tiene en cuenta dicho daño a la hora de establecer el gravamen, dado que según el art. 18 del citado texto refundido, la base imponible para la actividad de transporte de energía eléctrica, telefonía y telemática «estará constituida por la extensión de las estructuras fijas expresadas en kilómetros y en número de postes o antenas no conectadas entre sí por cables», y la cuota tributaria se fija en dichas actividades en «601,01 euros por kilómetro, poste o antena obtenidos conforme a lo dispuesto en el artículo 18 de esta Ley». La acusada similitud con el impuesto aragonés sobre el daño causado por la instalación de transportes por cable en cuanto a los elementos de cuantificación ${ }^{74}$, bien podría permitir afirmar que el impuesto extremeño sirve a la protección del paisaje $\mathrm{e}^{75}$-al menos- tan bien como el impuesto aragonés.

72 DO. Extremadura 23 diciembre 2006, núm. 150.

${ }^{73} \mathrm{Ni}$ en la norma que lo estableció originalmente, la Ley 7/1997, de 29 mayo, de Medidas fiscales sobre la producción y transporte de energía que incidan sobre el Medio Ambiente. DO. Extremadura 28 junio 1997, núm. 75; ni en la Ley 8/2005, de 27 diciembre, de Reforma de Tributos Propios de la Comunidad Autónoma de Extremadura, DO. Extremadura 31 diciembre 2005, núm. 150, que lo reformó en cumplimiento del Acuerdo de la Comisión Bilateral de Cooperación de la Administración General del Estado y la Comunidad Autónoma de Extremadura, publicado en el BOE de 26 de mayo de 2005, ni en el vigente texto refundido.

${ }^{74}$ Similitud que es puesta de manifiesto por Cremades Schulz M. T.: «Los impuestos sobre instalaciones que inciden en el medio ambiente» en Bécker F., et al., Tratado..., cit. p. 690. Para Patón García G., la base imponible para la actividad de transporte de energía eléctrica, telefonía y telemática sería un índice de que el impuesto se dirige a gravar el riesgo medioambiental producido por determinadas actividades productivas, «Hacia un modelo...» cit. pp. 64 y 82. También para Rodríguez Muñoz de la base imponible para esta actividad «se infiere igualmente la relación entre la base imponible del impuesto y la capacidad contaminante, el daño al medio, y su probabilidad de riesgo», Rodríguez Muñoz J. M.: «Los tributos...», cit. pp. 53-54 y 57. Quizás estemos ante uno de los supuestos señalados por Cors Meya en los que «un determinado hecho imponible, entendido en un sentido amplio, incluyendo la base imponible, puede ser indicativo de otro hecho, de su correspondiente objeto del tributo en el impuesto, tal hecho índice también lo puede ser de un tercer hecho en otro impuesto, de otro objeto del tributo». Cors Meya X.: «Impuesto sobre grandes...», cit. p. 26.

${ }^{75}$ En opinión de Rosembuj T., se trataría de un impuesto territorial y no de un impuesto ambiental, «Los impuestos ambientales...», cit. p. 15. 
De hecho, Rozas Valdés considera -de forma, bien es cierto, que parece irónica- que este impuesto, «el bien jurídico que trata de preservar, a tenor de su ámbito objetivo, y aunque no se diga expresamente, parece ser una cierta idea del paisaje. Lo que se sujeta a gravamen no es ni la emisión o vertido de sustancias contaminantes ni la realización de actividades de riesgo. No pretende modificar o reducir los índices de polución atmosférica, del suelo o de las aguas, pues no contempla medidas alternativas, ni se modula la cuota en función de comportamientos más sostenibles en términos ecológicos. Sencillamente se establece un impuesto patrimonial sobre la propiedad de determinados bienes -instalaciones de energía eléctrica y telecomunicaciones-que, asi se ha de entender, perturban el paisaje extremeño». Aunque -de forma menos irónica- pone de manifiesto que «si el bien jurídico medioambiental que se trata de preservar es el paisaje, sería cuando menos discutible la exención de la (energía) eólica o solar» y critica, por la misma razón, la exención subjetiva establecida a favor del Estado, la Comunidad Autónoma, las Corporaciones locales y sus Organismos Autónomos de carácter administrativo ${ }^{76}$. También Jiménez Hernández plantea la posibilidad de que el tributo extremeño, en su configuración original, «pretendiera salvaguardar con este tributo la belleza paisajística de Extremadura, eligiendo con ello el paisaje como bien jurídico concreto objeto de la tutela», como forma de salvar la falta de conexión entre el daño medioambiental y la titularidad de bienes afectos a determinada actividad que constituía el objeto imponible del impuesto. También critica, por la razón aludida, la exención subjetiva y la determinación de la base imponible como el valor de las instalaciones: "Podemos entender que unas instalaciones fabriles rompan la armonía paisajística y constituyan así un atentado contra el medio ambiente. Sin embargo, el valor de las instalaciones no indica el grado con que dicha instalación o estructura dáñale entorno» y considera más coherente la forma de determinación de la base imponible prevista para el transporte de energía, telefonía y telemática, con la afectación de su paisaje $^{77}$.

También, creado por la Ley 4/1997, Ley de Protección Civil de Cataluña, de 20 mayo $^{78}$, sujeta en el apartado sexto de su artículo 59 las instalaciones y estructuras destinadas al transporte o suministro de energía eléctrica, de acuerdo con una tarifa que grava dichas instalaciones y estructuras en fun-

${ }^{76}$ Rozas Valdés J. A.: «Riesgo de contaminar y tributos autonómicos» en Quincena Fiscal, núm. 2/2006, pp. 26-28.

77 Jiménez Hernández J.: «Comentarios acerca del impuesto sobre instalaciones que incidan en el medio ambiente de la Comunidad Autónoma de Extremadura» en Impuestos, vol. I, 1999, pp. 1361-1363 y 1367-1368.

${ }^{78}$ DO. Generalitat de Catalunya 29 mayo 1997, núm. 2401; rect. DO. Generalitat de Catalunya 5 junio 1997, núm. 2406. 
ción de los metros de las mismas ${ }^{79}$, si bien es cierto que atiende también a la mayor o menor potencia, medida en kilovoltios, del suministro; lo que, en opinión de Varona Alabern sería índice del «riesgo generado por la actividad, aunque los criterios para su medida puedan ser discutibles o carezcan de la suficiente precisión» ${ }^{80}$. El TC en su STC 168/2004, de 6 de octubre, declara «que el objeto de gravamen no son dichos elementos patrimoniales, sino el riesgo potencial de las actividades e instalaciones alli mencionadas» y afirma que «el gravamen no es un tributo de carácter contributivo, sino que prima su vertiente retributiva, pues su exacción no depende del valor del bien o de la renta que potencialmente produzca, sino del riesgo que encierra, de su peligrosidad, medido en términos de protección civil $\rangle^{81}$.

Cabe recordad a este respecto el pronunciamiento del Tribunal Constitucional en su STC 2006/179, que declaró la inconstitucionalidad de la redacción original del Impuesto Extremeño sobre Instalaciones que inciden en el Medio Ambiente, en la que se afirma que «...desconecta la cuantía del gravamen de la potencial actividad contaminante -o, dicho de otro modo, desconoce el principio en virtud del cual 'quien contamina paga'- (...) Como puede apreciarse, la magnitud del gravamen no la determina entonces la mayor o menor incidencia en el medio ambiente de las instalaciones sometidas a tributación, sino única y exclusivamente la mayor o menor facturación, producción o número de instalaciones de las actividades gravadas (...) no cabe considerar que el impuesto extremeño cuestionado grave efectivamente la actividad contaminante cuando desconoce el impacto ambiental en que incurren los sujetos llamados a soportarlo, o lo que es lo mismo, la medida en la que cada uno afecta al medio ambiente».

79 «Sexto. Las instalaciones y estructuras destinadas al transporte o suministro de energía eléctrica, de acuerdo con la siguiente tarifa:

a) Entre 26 y 110 kilovoltios: 0,1 pesetas por metro.

b) Entre 111 y 220 kilovoltios: 0,5 pesetas por metro.

c) Entre 221 y 400 kilovoltios: 1 peseta por metro.

d) Más de 400 kilovoltios: 4 pesetas por metro».

${ }^{80}$ Varona Alabern J. E.: «El tributo catalán creado por la Ley de Protección Civil de Cataluña y la STC 168/2004, de 6 de octubre», en Nueva Fiscalidad, núm. 6/2006, p. 19. También para Luchena Mozo G. M., y Patón García G., el impuesto «tiene como fin el gravamen preventivo de actividades que puedan ser inequívocamente causantes de algún daño ambiental», «Las líneas actuales de gravamen en la tributación medioambiental» en Quincena Fiscal, núm. 18/2005, p. 28.

${ }^{81}$ FJ $10{ }^{\circ}$. Sobre la STC y la posible traslación de los argumentos contenidos en ella a otros tributos autonómicos análogos, como el impuesto extremeño sobre la producción y el transporte de energía: Rodríguez Muñoz J. M.: «Los tributos sobre actividades de riesgo. Su consagración a raíz de la STC 168/2004, de 6 de octubre de 2004 y la aplicación de esta sentencia a otros impuestos autonómicos sub iudice» en Nueva Fiscalidad, núm. 4/2005, pp. 40-60. 
También resulta pertinente recordar que, según señala una autorizada doctrina, en los tributos ambientales, en los que el gravamen debería incentivar la reducción del daño ambiental, «si este se mide a través de factores medio o indiciarios, el incentivo desaparece, pues los esfuerzos por reducir la contaminación no se verán reflejados en la base ni en la cuota. De este modo el impuesto deja de ser idóneo para cumplir su fin y desaparece la justificación extrafiscal de una tributación que difiere del principio de capacidad económica. Esto supone, en definitiva, la inconstitucionalidad de los tributos medioambientales que incurran en tales deficiencias. Por ello, el régimen de estimación objetiva ha de basarse en elementos que constituyen un incentivo a reducir la contaminación, como el tipo de instalaciones o de materias primas utilizadas en los procesos productivos. En conclusión, si la estimación objetiva constituye el supuesto normal de aplicación del tributo y en dicho régimen no existe ningún estímulo a reducir la contaminación, el tributo no resulta idóneo para cumplir la finalidad que lo justifica» ${ }^{82}$. Es más, «cuando es débil el vínculo entre la base imponible del impuesto y los daños producidos al medio ambiente, el impuesto corre el riesgo de no ejercer el impacto deseado en este y, paralelamente, de introducir distorsiones inútiles y costosas en las decisiones de producción y consumo» ${ }^{83}$. Tal y como señala Patón en relación con el impuesto extremeño, dada su escasa virtualidad recaudatoria, «las actividades de producción o transporte de energía seguirán realizándose en la medida en que los intereses económicos de las empresas respectivas se lo permitan, sin que tenga una influencia crucial en ello la existencia del impuesto» ${ }^{84}$.

\section{El impuesto sobre el daño medioambiental causado por las grandes áreas de venta de la Comunidad Autónoma de Aragón y el paisaje}

El impuesto sobre el daño medioambiental causado por las grandes áreas de venta fue establecido en Aragón también por la Ley 13/2005, en la que se define como su objeto «gravar la concreta capacidad económica manifestada en la actividad y el tráfico desarrollados en establecimientos comerciales que, por su efecto de atracción al consumo, provoca un desplazamiento masivo de vehículos y, en consecuencia, una incidencia negativa en el entorno natural y territorial de la Comunidad Autónoma de Aragón ${ }^{85}$,

\footnotetext{
${ }^{82}$ Herrera Molina P.: «Derecho Tributario ambiental...», cit. p. 175.

${ }^{83}$ OCDE: La fiscalidad y el medio ambiente. Políticas complementarias, Madrid, 1994, p. 58 .

${ }^{84}$ Patón García G.: «Hacia un modelo...», cit. p. 64.

${ }^{85} \mathrm{Si}$ bien la ley aragonesa no hace referencia alguna a ninguna otra finalidad, a diferencia de lo que sucede en las leyes navarra (Ley Foral del Impuesto sobre los Grandes Establecimientos Comerciales de Navarra, Ley Foral 23/2001, de 27 noviembre, BO. Navarra 7
} 
sin hacer referencia alguna al eventual daño en el paisaje provocado por dichos establecimientos, aunque el art.9 de la misma (actual art. 2 del vigente Texto Refundido) declara como finalidad común a todos los impuestos medioambientales «gravar la concreta capacidad económica que se manifiesta, como riqueza real o potencial susceptible de imposición, en el daño causado en el medio ambiente por determinadas elementos, conductas y actividades contaminantes, que se realizan o desarrollan mediante la explotación selectiva, la degradación o la lesión de los recursos naturales y que provocan un grave deterioro en el medio natural, territorial y paisajístico de la Comunidad Autónoma de Aragón».

Tal y como señala la exposición de motivos de la ley «el impacto añadido sobre el medio urbanístico y territorial, que agrava considerablemente el daño producido, es considerado por la Ley atendiendo a la mayor variación en la tipología territorial en que estas actividades comerciales pueden llevarse a cabo. La Ley Urbanística de Aragón ofrece diferentes clases y tipologías de suelo en función de su finalidad y su propensión a la transformación y desarrollo urbanizador que se considera necesario preservar. A la vista de esta clasificación, parece claro que la incidencia sobre el medio ambiente, desde un punto de vista territorial, será considerablemente diferente en función de que la actividad a desarrollar se ubique en un suelo perfectamente integrado en el proceso urbanizador o se ubique en un tipo de suelo en el que concurran ciertos valores que es necesario proteger. Un gran establecimiento comercial ubicado en suelo urbano, asimilado en su entorno y su paisaje urbanístico, en el que existe posibilidad de acceso peatonal, que se encuentra integrado en el área operativa de la red de transportes públicos y que, en fin, vertebra una determinada zona comercial, de ocio y

diciembre 2001, núm. 148), asturiana (Ley de Medidas Presupuestarias, Administrativas y Fiscales, Ley 15/2002, de 27 diciembre, BO. del Principado de Asturias 31 diciembre 2002, núm. 301; rect. BO. del Principado de Asturias 31 enero 2003, núm. 25) o catalana (Ley del Impuesto sobre Grandes Establecimientos Comerciales de la Generalitat de Catalunya, Ley 16/2000, de 29 diciembre, DO. Generalitat de Catalunya 30 diciembre 2000, núm. 3295; rect. DO. Generalitat de Catalunya 7 febrero 2001, núm. 3322). Cabe preguntarse con la profesora Soler «hasta qué punto el objeto-fin (la protección del medio ambiente), no se proclama solo para enmascarar la auténtica finalidad del tributo, de modo que la invocación de la defensa del medio ambiente no pasa de ser meramente formal a efectos de legitimar un impuesto cuyo objetivo real es distinto (en este caso, la protección del pequeño comercio)». Soler Roch M. T.: «El principio...», cit. p. 96. También cabe preguntarse si son realmente varias las causas que justificarían el gravamen -como se declara en las leyes de las restantes comunidades (compensar el daño ambiental, la protección del territorio y la protección del comercio minorista)-, si se ha reparado en la inevitable colisión entre ellas y la consecuente incoherencia interna del tributo, que denuncian en relación con el impuesto asturiano Sesma Sánchez B., y Cordero González E. M.: «El impuesto sobre grandes establecimientos comerciales del Principado de Asturias» en Revista de Información Fiscal, núm. 72/2005, pp. 90 y 91, y en relación con el catalán Zornoza Pérez J., y Ruiz Almendral $\mathrm{V} .:$ «El impuesto...», cit. p. 35 y pp. $78-79$. 
de servicios en la ciudad, no produce el mismo impacto ambiental y territorial que otro establecimiento instalado en otro tipo de suelo, ubicado en la periferia de los contornos urbanos y fuera del alcance de los transportes públicos. En atención a estas consideraciones, el impuesto ha previsto la aplicación de unos coeficientes correctores sobre la cuota tributaria, distinguiendo si se trata de suelo urbano, urbanizable, delimitado y no delimitado, con anterioridad o posterioridad a la aprobación del Plan Parcial, no urbanizable genérico y no urbanizable especial».

En efecto, tal y como se establece en el art. 28.2 del vigente texto refundido, a la cuota tributaria se le aplican «en función de la clase y tipología del suelo en el que esté ubicada la gran superficie comercial, el coeficiente que corresponda entre los siguientes:

a) En suelo urbano: 1 .

b) En suelo urbanizable, delimitado o no delimitado, con posterioridad a la aprobación del Plan Parcial correspondiente: 1,10.

c) En suelo urbanizable no delimitado, con anterioridad a la aprobación del Plan Parcial, o en suelo no urbanizable genérico: 1,25.

d) En suelo no urbanizable especial: 1,5».

Lo que supone incrementar hasta un 50\% el importe del impuesto, en función de la clase y tipología del suelo ${ }^{86}$.

Pues bien, tal y como dispone el art. 19.a de la Ley Urbanística de Aragón, Ley 5/1999, de 25 marzo $^{87}$, tendrán la condición de suelo no urbanizable los terrenos clasificados como tales por el planeamiento por concurrir alguna de las circunstancias siguientes:

«a) En todo caso, el suelo preservado de su transformación mediante la urbanización, que deberá incluir, como mínimo, los terrenos excluidos de dicha transformación por la legislación de protección o policía del dominio público, de la naturaleza o de patrimonio cultural; los que deban quedar sujetos a tal protección conforme a la ordenación territorial y urbanística por los valores en ellos concurrentes, incluso los ecológicos, agrícolas, ganaderos, forestales y paisajísticos...» (el subrayado es mío). Suelos a los que el art. 20 atribuye el carácter de suelo no urbanizable especial:

«1. En el suelo no urbanizable se distinguirán las categorías de suelo no urbanizable genérico y suelo no urbanizable especial. (...)

${ }^{86}$ En opinión de Sánchez Graells, la utilización de este criterio de graduación del gravamen sería contrario a los principios constitucionales que regulan el ejercicio de la potestad tributaria y supone una verdadera desnaturalización de la extrafiscalidad del impuesto aragonés, al estar más bien diseñado para penalizar determinados modelos de desarrollo de la actividad del comercio minorista con un carácter más bien sancionatorio. Sánchez Graells A.: «La inconstitucionalidad del nuevo impuesto aragonés sobre el daño causado por las grandes áreas de venta» en Quincena Fiscal, núms. 15-16/2006, p. 37.

${ }^{87}$ BO. Aragón 6 abril 1999, núm. 39. 
2. Tendrán la consideración de suelo no urbanizable especial los terrenos del suelo no urbanizable a los que el Plan General reconozca tal carácter y en todo caso los enumerados en la letra a) del artículo anterior...».

Por lo tanto, cuando los valores paisajísticos concurrentes en el suelo en el que está ubicada la superficie comercial hayan determinado su calificación como «suelo no urbanizable especial», la cuota tributaria se verá incrementada en un 50\%. De nuevo, dado que el coeficiente corrector se aplica sobre una cuota íntegra que resulta de la aplicación de una tarifa progresiva en función de la superficie en la que se mide la base imponible del impuesto, que es determinada en función de unos parámetros (superficie de venta, superficie destinada a servicios comunes o auxiliares y de espacios comunes de paso, superficie de aparcamiento) que poco o nada tienen que ver con el impacto añadido sobre el medio y paisaje urbanístico y territorial que a través de la aplicación de los coeficientes se trataría de desincentivar.

Por otra parte, teniendo presente que en el impuesto aragonés, según dispone el art. 25 del texto refundido, «son sujetos pasivos del impuesto, en calidad de contribuyentes, los titulares de la actividad y el tráfico comercial que propicien el daño en el medio ambiente gravado por el impuesto», de forma congruente con la definición del hecho imponible en el art. 23 del mismo texto legal como «el daño medioambiental causado por la utilización de las instalaciones y elementos afectos a la actividad y al tráfico desarrollados en los establecimientos comerciales que dispongan de una gran área de venta y de aparcamiento para sus clientes y se encuentren ubicados en el territorio de la Comunidad Autónoma de Aragón», resultaría difícil imputar, salvo de forma indirecta, la causación del daño en el medio ambiente ${ }^{88}$ que se pretende desincentivar con los recargos establecidos en el art. 28.2 del texto refundido, a quien, pese a ser titular de la actividad y el tráfico comercial, al no ser propietario del inmueble, puede no haber tenido parte en la decisión relativa a la ubicación del centro comercial en un tipo de suelo u otro y, en definitiva, se encuentra con que el «impacto ambiental y territorial» que se pretende desincentivar con dichos coeficientes correctores ya se ha producido en el momento en que, al comenzar a ejercer su actividad, se convierte en sujeto pasivo del impuesto y, en función de ello, difícilmente puede hacer nada para disminuir dicho daño ${ }^{89}$. Es más, dada la referida configuración del hecho imponible, podría darse el caso de que el impuesto no se exigiera, por no utilizarse las instalaciones, pese a que el impacto sobre el medio y paisaje urbanístico y territorial se ha consumado con la mera construcción del establecimiento.

${ }^{88}$ Razón, quizás, por la cual la ley utiliza el término «propiciar».

${ }^{89}$ A diferencia de lo que sucede en el impuesto asturiano, como señalan Sesma Sánchez B., y Cordero González E. M.: «El impuesto...», cit. pp. 112-114. 
En última instancia, cabe plantarse una vez más en qué medida este gravamen adicional, o incluso la totalidad del gravamen por el impuesto sobre el daño medioambiental causado por las grandes áreas de venta, puede realmente suponer un desincentivo real a la causación del daño medioambien$\mathrm{tal}^{90}$, si tenemos en cuenta la magnitud económica de los intereses comerciales y urbanísticos en juego en la construcción y explotación de este tipo de establecimientos comerciales y el hecho mismo de que su construcción en un suelo no urbanizable especial por los valores paisajísticos concurrentes en el mismo podría ser directamente evitada sin necesidad de acudir a desincentivo fiscal alguno. Quizás, tal y como afirma Rosembuj, «estamos llegando a un punto tal de saturación, que bien podría comenzar a pensarse en la subordinación de la ordenación y gobierno del territorio a la conservación y gestión del bien ambiental. La clave es dejar la transformación urbanística, privilegiando el suelo no edificable, aquella parte del territorio que auspicia la vida en común (...) La no edificabilidad, en suma, podría ser un valor sostenible del propietario forestal, del propietario rústico...»" .

Desde este punto de vista, resultaría ciertamente deseable para la protección del territorio y el paisaje una política fiscal más decididamente orientada a combatir el uso irracional del territorio constituido por la urbanización de baja densidad o suburban sprawl -con sus secuelas de incremento del tráfico rodado, contaminación subsiguiente, incremento de la extensión y coste de las infraestructuras, disminución en la cantidad y calidad del agua, etc.en la que el territorio se agota y el paisaje se degrada en una sucesión interminable de urbanizaciones de viviendas unifamiliares, centros comerciales, carreteras y aparcamientos, cada vez más alejados de los centros de trabajo y de los centros de las ciudades. Aunque el desincentivo a través de impuestos de finalidad extrafiscal que recaen sobre los grandes centros comerciales -cuya generalización está sin duda íntimamente ligada al desarrollo del fenómeno del sprawl y constituye uno de sus ingredientes esenciales: la separación entre zonas residenciales y comerciales- puede jugar un papel en la protección del territorio y el paisaje, una fiscalidad sobre los bienes inmuebles que en la valoración del suelo tuviera en cuenta las externalidades negativas que su irracional utilización provoca sería sin duda alguna más eficaz.

${ }^{90}$ Para Rosembuj T., «Es un impuesto de custodia del territorio, que no ambiental». «Los impuestos ambientales...», cit. p. 13.

${ }^{91}$ Rosembuj T.: «Los impuestos ambientales...», cit. p. 15. 